\title{
ROP MATHEMATICAL MODEL OF ROTARY-ULTRASONIC CORE DRILLING OF BRITTLE MATERIAL
}

\author{
Mera Fayez Horne ${ }^{1}$ \\ 1 Department of Mechanical Engineering, University of California Berkeley, 6141 Etcheverry Hall, MC 1740, \\ Berkeley, CA 94720, USA, e-mail: merahorne@berkeley.edu
}

Received: 2016.12.29

Accepted: 2017.02.09

Published: 2017.03.01

\begin{abstract}
The results from the Phoenix mission led scientists to believe it is possible that primitive life exists below the Martian surface. Therefore, drilling in Martian soil in search for organisms is the next logical step. Drilling on Mars is a major engineering challenge due to the drilling depth requirement and extreme environment condition. Mars lacks a thick atmosphere and a continuous magnetic field that shield the planet's surface from solar radiation and solar flares. As a result, the Martian surface is sterile and if life ever existed, it must be found below the surface. In 2001, NASA's Mars Exploration Payload Advisory Group proposed that drilling should be considered as a priority investigation on Mars in an effort of finding evidence of extinct or extant life. The results from the Curiosity mission suggested drilling six meters deep in the red planet in search for life. Excavation tools deployed to Mars so far have been able to drill to a maximum depth of $6.5 \mathrm{~cm}$. Thus, the drilling capabilities need to be increased by a factor of approximately 100 to achieve the goal of drilling six meters deep. This requirement puts a demand on developing new and more effective technologies to reach this goal. Previous research shows evidence of a promising drilling mechanism in rotary-ultrasonic for what it offers in terms of high surface quality, faster rate of penetration and higher material removal rate. This research addresses the need to understand the mechanics of the drill bit tip and rock interface in rotary-ultrasonic drilling performance of one drill bit at a time drilling in three types of rocks that vary in strength. A mathematical model identifying all contributing independent parameters, such as drill bit design parameters, drilling process parameters, ultrasonic wave amplitude and rocks' material properties, that have effect on rate of penetration is developed. Analytical and experimental results under ambient condition are presented to show the effect of the variation of different parameters on rate of penetration performance as a first step of the investigation. It was found that the speed and WOB have significant effect on ROP while the rest of the parameter have very little or no effect.
\end{abstract}

Keywords: rotary ultrasonic, brittle, ROP, Mars, rocks, abrasive, fracture, drilling

\section{ROTARY-ULTRASONIC DRILLING MECHANICS}

While purely ultrasonic drilling showed great promise in the laberatory, field tests using such drilling tool, including the ultrasonic/sonic gopher in Antarctica, have shown significant limitation on the the powdered cuttings removal rate necessary to achieve rapid deep-hole drilling as stated by Badescu [2]. This limitation was the main motivation behind the consideration of superimposing the ultrasonic mechanisms in drilling with the rotary action to achieve higher material removal rate and reach greater depths. A rotary percussion was designed to introduce the rotation capability and the ultrasonic vibration combined as it stated by Badescu [3]. To ensure a robust mechanisms, the actuations of the rotation and hammering functions were decopuled, using one as a backup system in a case of the failure of 
the other. The dual action mechanics enhanced the drilling process significantly. In addition, various ultrasonic drilling paramters need to be handled with special care in the effort to reach optimum drilling process such as, matching resonance of the drilling device and using the proper horn design to achieve the desired amplitude magnification as described below.

\section{Rotary and oscillation dual action mechanics}

To achieve rotary and oscillation dual action, the drilling system will consist of the major following components (Figure 1) [http://www.decoup.com/en/content/how-does-it-work].

Power supply (converts $60 \mathrm{~Hz}$ electrical supply to high frequency $(>20 \mathrm{kHz}) \mathrm{AC}$ electrical output fed to the piezoelectric transducer).

\section{Ultrasonic spindle}

Piezoelectric transducer that converts electrical input from the power supply into mechanical vibrations. Motor attached atop the ultrasonic spindle that supplies the rotating motion of the core drill (not shown in the figure). Motor speed controller that can be adjusted to obtain different motor speeds. Specimen fixture that holds the specimen and it is mounted on a dynamometer that is attached to the machine table.

\section{Data acquisition system}

Piezoelectric dynamometer (measures the cutting force along feed direction producing an electrical signal and fed to $\mathrm{A} / \mathrm{D}$ converter). $\mathrm{A} / \mathrm{D}$ converter (converts electrical signals from the dynamometer into numerical signals that are displayed and saved on a computer system). Computer is typically equipped with a device that displays and saves the numerical signals coming from the A/D converter.

\section{Axial oscillation dynamics}

Axial oscillation is generated from vibrations in the range of sonic or ultrasonic range $(>20 \mathrm{kHz}$ frequency) (Terralog Technologies Inc.) The oscillation effect takes three major states during the process of drilling. Hammering force is generated upon the impact of the percussive/vibrational oscillation slowly builds up between the drill bit cutting edge and the rock point of contact and gradually crushes and compact rock's irregular surface. The rapidly increased force develops subsurface cracks in the rock radially outwards from the stress concentration lines at the bit cutting edge outer boundaries. Finally, rock fatigue due to cyclic loading is an additional dynamic that has effect on percussive/vibrational (sonic/ultrasonic) drilling mechanism. Rock fatigue is not a part of the mathematical model developed in this research.

The rock workpiece during percussion drilling is exposed to uniaxial compression type of loading at the bit-rock interface. Literature shows that the rock uniaxial compressive strength (UCS) is weakened by approximately $75 \%$ in percussive drilling as discussed by Bar-Cohen [4]. Although this result was not closely examined by the oil industry until late the 1970s due to its high level of uncertainly, it is an invaluable finding as the fundamental mechanisms for rock damage during percussive /ultrasonic drilling. The fact of the UCS drop in percussive drilling may explain the fact that the process is faster than traditional rotary drilling since the rock is weakened and easily fractured due to the developed microfractures in the materials. In this research, the main goal is to determine the rotary ultrasonic drilling performance in brittle material (rock) as a drilling mechanism.

\section{Rotary dynamics}

As the materials are already fractured due to the vertical oscillation, the built up stress in the
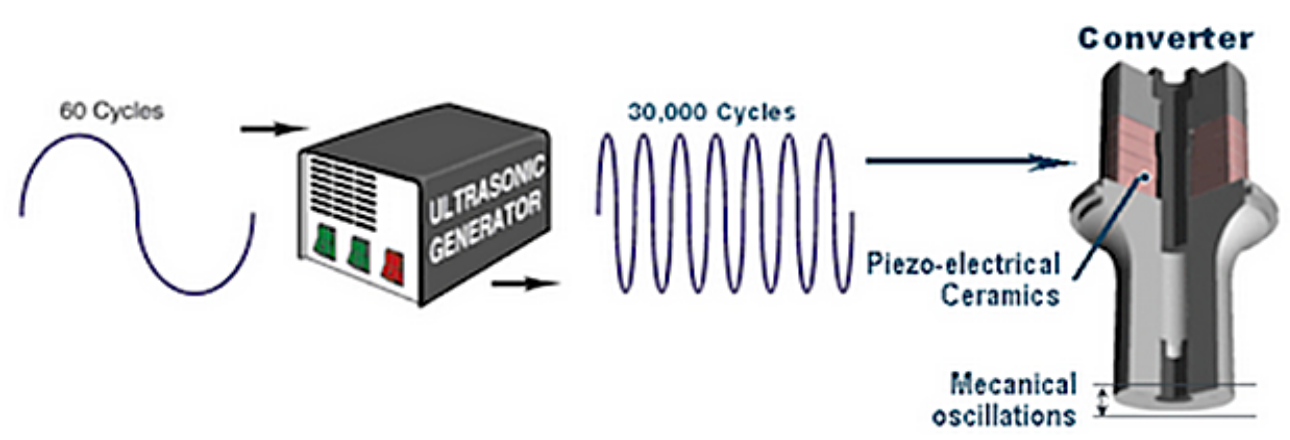

Figure 1. Ultrasonic device schematic of the operation concept, decoup site 
plane due to the rotary motion is relieved through the shear fractures along the thrust direction allowing the cuttings to be removed. The clearance of the cutting materials allows the drill bit to penetrate further achieving greater depth and overcoming the purely ultrasonic limitation mentioned previously.

Literature shows evidence of higher performance of rotary ultrasonic compared with the traditional rotary drilling where the static and lower WOB applied. For example, ROP of $3.3 \mathrm{~m} / \mathrm{h}$ was achieved with the 8.75 inch bit when WOB is $44.84 \mathrm{kN}$. While in rotary drilling mode, 184.33 $\mathrm{kN}$ of WOB is needed to achieve the same ROP (Melamed, 2000). Also, the less contact time with rock that lead to less drill bit abrasion and longer bit life where only $1-2 \%$ of total operational drilling time [Bates 1965, Melamed et al. 2000].

\section{ROP MATHEMATICAL MODEL DEVELOPMENT}

\section{Outline of model development}

The analysis begins with a consideration of the motion of a single abrasive particle due to the rotation of the bit and the superimposed ultrasonic vibration. This leads to an expression for the position and velocity of the particle as functions of time. The expression contains the following parameters, with the units used given in parentheses: distance from the axis to the abrasive particle $r$ (m), amplitude of the ultrasonic excitation $A(\mathrm{~m})$, angular velocity of drill bit $\omega_{r}, f_{r}, S(\mathrm{rad} / \mathrm{s}, \mathrm{Hz}$, $\mathrm{rpm})$, ultrasonic frequency $\omega_{u}, f_{u}(\mathrm{rad} / \mathrm{s}, \mathrm{Hz})$ and rate of advance of bit into the workpiece $b(\mathrm{~m} / \mathrm{s})$.

Next, the effective cutting time and effective length are introduced in terms of the (unknown) maximum depth of penetration that the abrasive particle experiences as it travels below the surface of the workpiece. The expressions developed contain the following parameters: maximum depth that the abrasive particle travels $\delta(\mathrm{m})$, time right before the particle cuts into workpiece $t_{1}(\mathrm{~s})$, time the particle reaches the maximum depth $t_{2}$ (s), time the particle ends cutting $t_{3}(\mathrm{~s})$, effective total time the particle is cutting $\Delta t(\mathrm{~s})$ and the distance traveled during the effective time $L_{s}(\mathrm{~m})$.

An analysis of Vickers indentation of brittle materials is then used to relate the maximum depth of penetration to the force necessary to achieve this depth. This gives an explicit function relating and the force or vice versa. The expres- sions introduce the following parameters: Vickers hardness of the rock $H_{v}(\mathrm{~Pa})$, force applied to a single particle $F_{n}(\mathrm{~N})$, angle between faces of abrasive particle $\alpha_{o}(\mathrm{rad})$.

Total force applied to the drill bit (or weighton-bit) is determined by relating it to the sum of $F_{n}$ applied to total number of particles that involved in cutting process and the time spent each particle spends cutting $(\Delta t)$. The expressions introduce the following parameters: force applied to drill bit $F(\mathrm{~N})$, number of abrasive particles take part in cutting $N_{a}(-)$, particle concentration $C_{a}(-)$, abrasive particle size $S_{a}(\mathrm{~m})$, drill bit face area $A_{o}\left(\mathrm{~m}^{2}\right)$.

The next step involves determining the material removal rate for a single particle in terms of the fracture characteristics of a brittle material under an indenter as it cuts into the material. Of particular interest are the length and depth of the lateral cracks that form under the indenter as these two lengths, along with the distance traveled by the particle during the cutting process, provide an estimate of the volume of material that is chipped out of the workpiece during a single ultrasonic cycle. The model expressions used introduces the following parameters: lateral crack length $C_{L}(\mathrm{~m})$, lateral crack height $C_{h}(\mathrm{~m})$, volume proportionality $K(-)$, Young's modulus of the workpiece $E$ $(\mathrm{Pa})$, Poisson's ratio of the workpiece $v(-)$ and fracture toughness of the workpiece $K_{I C}(\mathrm{~Pa} \sqrt{\mathrm{m}})$.

Finally, the total material removal rate is determined in two ways: as the material removal rate of all of the particles and as the product of the area times the rate of penetration, which then leads to equations giving ROP as a function of both $F$ and $\delta$. At this point, the solution depends on going back to the relations between $F$ and $\delta$, or alternatively $\delta$ and $F$.

\section{Model introduction}

A variety of research has been conducted on rotary-ultrasonic machining of brittle materials relating the material removal rate and cutting force. However, none of them addressed the process for hole drilling in brittle materials. In this research, a rate-of-penetration mathematical model is developed utilizing a previously published mathematical model for cutting force in rotaryultrasonic milling of brittle materials as discussed by Zhang [14]. The basis for this model involves the material brittle fracture removal mechanism. In the previous research of Zhang, the essential 
approach to the cutting force model was developed by analyzing a single abrasive particle as the basic component of cutting forces in a diamond drill bit (Figure 2). The model was derived by summing up all forces exerted by all diamond particles taking part in cutting, which was published in many papers for the cutting force models of variety of abrasive particles.

First, I will address the fracture concept and assumptions shared in both research, as well as the common parameters of both equations and how some of them are different for drilling versus milling.

\section{Fracture concept and assumptions}

The following is a list of assumptions developed particularly for the materials in consideration in this research, which are brittle materials. While the material removal modes may vary, brittle material removal is the primary mode. All workpieces used in this study are ideal brittle materials. Therefore, the brittle fracture removal

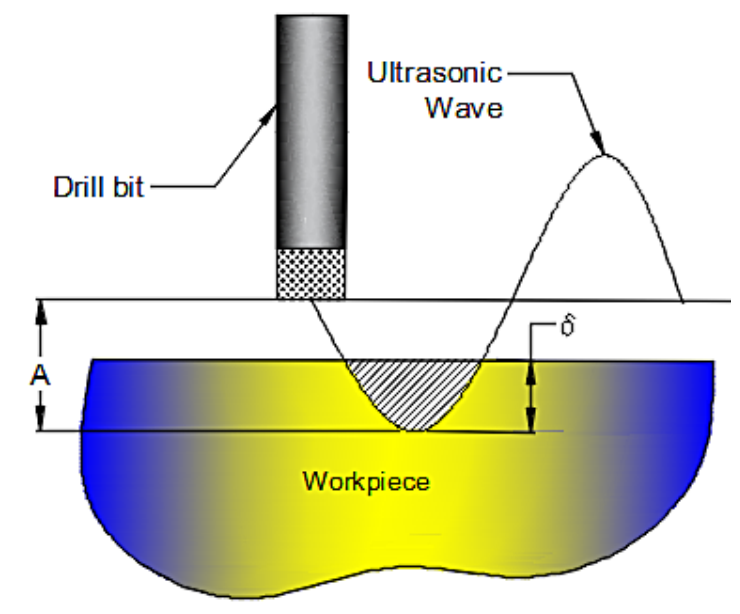

Figure 2. Modified illustration of Rotary Ultrasonic Milling (RUM) process for downhole drilling and core drill bit
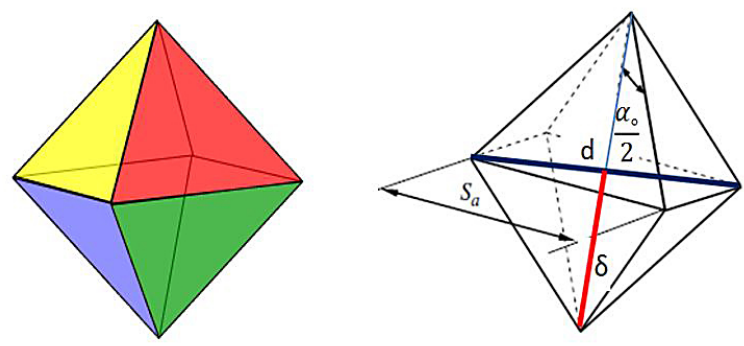

Figure 3. Abrasive particle simplified as an octahedron shape [http://paulscottinfo.ipage.com/polyhedra/ platonic/octahedron/1octahedronL.gif] mechanism applies to the removed materials on the workpiece surface in brittle fracture mode as discussed by Arif [1].

All cutting particles (diamond) in the drill bit cross section take part in cutting. All diamond particles are rigid octahedrons shape of the same size with equal side length for the twelve sides $\left(S_{a}\right)$ (Figure 3). Each diamond particle has one sharp corner of the octahedron shape (one corner for each particle) that acts on the workpiece surface with the same mechanics as a Vickers indenter.

\section{MATHEMATICAL MODEL PARAMETERS}

\section{Abrasive particle position and velocity}

The kinematic motion of one abrasive particle can be expressed in terms of the position and velocity of the particle. Considering the dual motion of the drill bit that combines rotational motion of counterclockwise rotation in the x-y plane, coupled with vertical vibration of the ultrasonic wave in the tool axis / feed direction (Figure 4).

Variables used in developing the mathematical model, definitions, symbols and measuring units are listed in Table 1.

Starting with a helix path (Figure 5) in the drilling process of a drill bit with rotational speed, in the $\mathrm{x}-\mathrm{y}$ plane and speed $b$ downwards in the $\mathrm{z}$ direction, the position $S_{p}$ of one abrasive particle is:

$$
S_{p}=\left[\begin{array}{c}
r \cdot \sin \left(\omega_{r} t\right) \\
r \cdot \cos \left(\omega_{r} t\right) \\
A \cdot \sin \left(\omega_{u} t\right)+b t
\end{array}\right]
$$

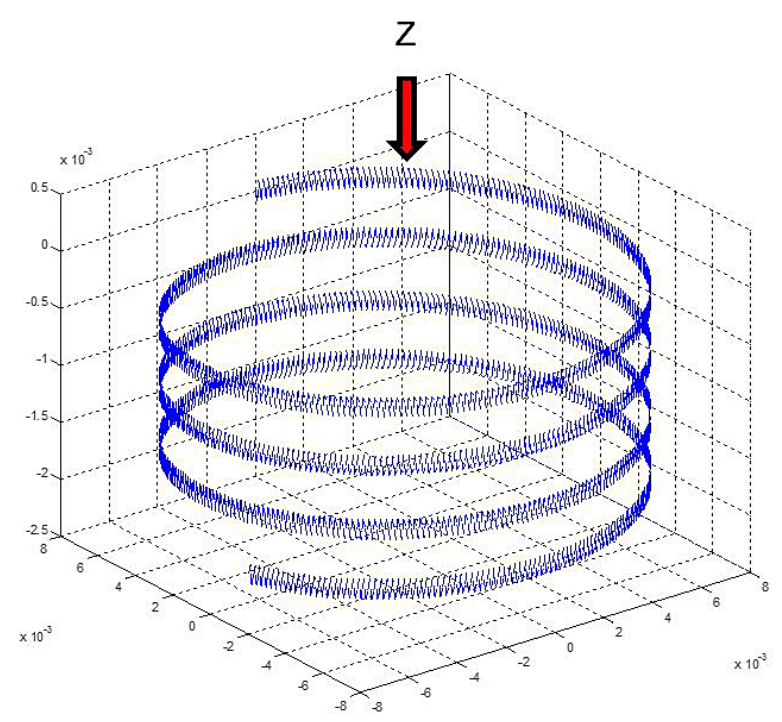

Figure 4. Ultrasonic wave superimposed on rotary motion of an abrasive particle mounted on the cutting surface of a drill bit 
Table 1. Input variables, definitions, symbols, and units

\begin{tabular}{|c|c|c|}
\hline Input variables & Definitions and symbols & Units \\
\hline \multirow{4}{*}{$\begin{array}{l}\text { Drill bit / diamond } \\
\text { variables }\end{array}$} & 1. Drill bit outer diameter, $D_{s}$ & $\mathrm{~mm}$ \\
\hline & 2. Drill bit inner diameter, $D_{i}$ & $\mathrm{~mm}$ \\
\hline & 3. Abrasive concentration, $C_{a}$ & unitless \\
\hline & 4. Abrasive size, $S_{a}$ & $\mathrm{~mm}$ \\
\hline \multirow{3}{*}{$\begin{array}{l}\text { Machining process } \\
\text { variables }\end{array}$} & 5. Spindle speed, S & rpm \\
\hline & 6. Applied force (WOB), $F$ & $\mathrm{~N}$ \\
\hline & 7. Feed rate, $f_{r}$ & $\mathrm{~mm} / \mathrm{s}$ \\
\hline \multirow{2}{*}{$\begin{array}{l}\text { Ultrasonic vibration } \\
\text { variables }\end{array}$} & 8. Amplitude, $A$ & $\mu \mathrm{m}$ \\
\hline & 9. Frequency, $f_{u}$ & $\mathrm{~Hz}$ \\
\hline \multirow{4}{*}{$\begin{array}{l}\text { Workpiece material } \\
\text { properties }\end{array}$} & 10. Elastic modulus, $E$ & GPa \\
\hline & 11. Poisson's ration, $v$ & unitless \\
\hline & 12. Fracture toughness, $K_{I C}$ & $\mathrm{MPa} \sqrt{\mathrm{mm}}$ \\
\hline & 13. Hardness, $H_{v}$ & $\mathrm{MPa}$ \\
\hline
\end{tabular}

The velocity $\left(V_{p}\right)$ is then:

$$
V_{p}=\frac{d S_{p}}{d t}=\left[\begin{array}{c}
r \cdot \omega_{r} \cdot \cos \left(\omega_{r} t\right) \\
-r \cdot \omega_{r} \cdot \sin \left(\omega_{r} t\right) \\
A \cdot \omega_{u} \cdot \cos \left(\omega_{u} t\right)+b
\end{array}\right]
$$

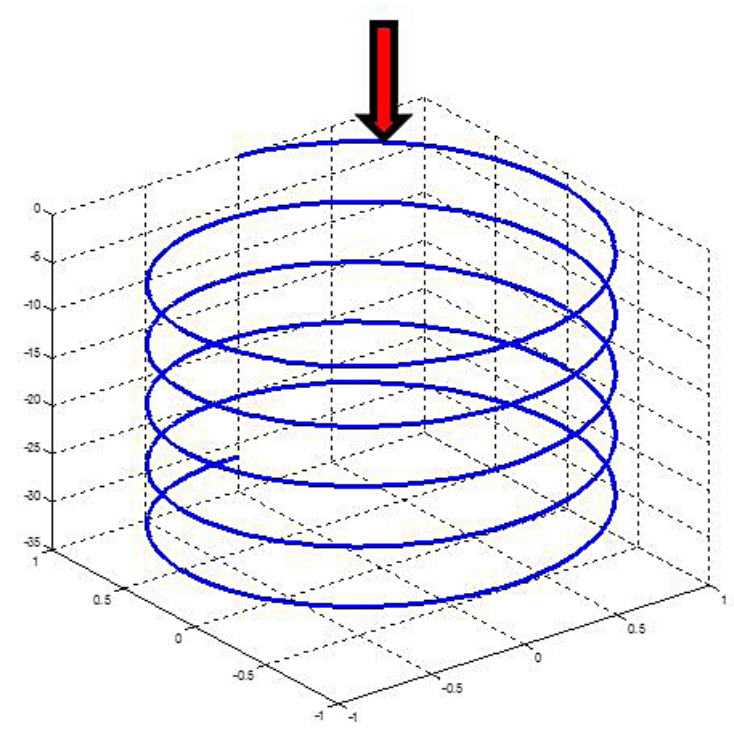

Figure 5. Drill bit tip helix path

Effective time $(\Delta t)$ - let the effective time be the time it takes for one abrasive particle to cut through the workpiece during one ultrasonic cycle as shown in Figure 6.

As the abrasive particle moves downwards during the first half of the ultrasonic sine wave, it starts cutting through the materials at $t_{1}$. It keeps cutting downwards until at time $t_{2}$, the abrasive particle reaches the maximum cutting depth in the workpiece. The abrasive particle progresses in cutting the material until it exits the workpiece

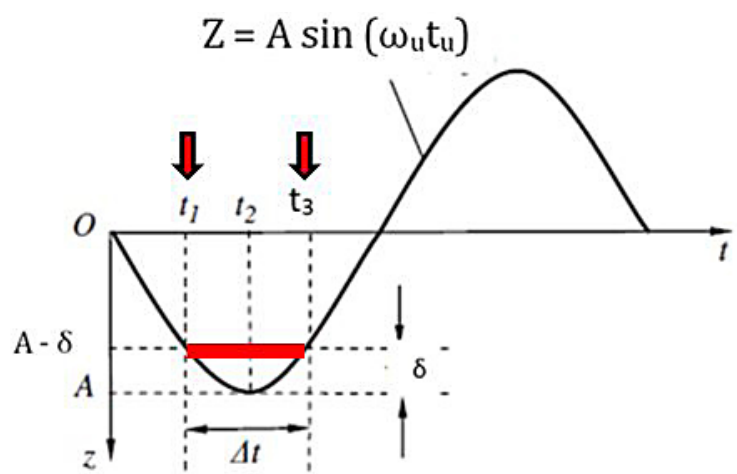

Figure 6. Effective time $(\Delta \mathrm{t})$ during one ultrasonic cycle

where: $Z$-ultrasonic wave equation,

$A$ - ultrasonic wave amplitude,

$\delta$ - maximum penetrated depth in the workpiece,

$t_{1}$ - time the abrasive particle begins to cut into the workpiece,

$t_{2}$ - the time the abrasive particle reaches the maximum depth,

$t_{3}$ - ending time for the abrasive particle to cut through and leaves the workpiece,

$\Delta t$ - effective time $=t_{3}-t_{1}$.

at time $\mathrm{t}_{3}$. The time duration between $t_{1}$ and $t_{3}$ is what is defined at the effective time $(\Delta t)$. Therefore:

$$
t_{2}-t_{1}=\frac{\mathrm{t} 3-\mathrm{t} 1}{2}=\frac{\Delta t}{2}
$$

The $\mathrm{Z}$ values at time $\mathrm{t}_{1}$, and $\mathrm{t}_{2}$ are:

$$
Z\left(t_{1}\right)=A-\delta=A \sin \left(\omega_{u} t_{1}\right),
$$

where: $\omega_{u}=2 \pi f_{u}$

Solving for $\left(t_{1}\right)$ gives:

$$
t_{1}=\frac{1}{2 \pi f_{u}} \arcsin \left(\frac{A-\delta}{A}\right)
$$

At the time of maximum depth, $Z\left(t_{2}\right)=A$

$$
t_{2}=\frac{1}{4 f_{u}}
$$

Manipulating the above equations and solving for $\Delta t$ :

$$
\Delta \mathrm{t}=\frac{1}{\pi f_{u}}\left[\frac{\pi}{2}-\arcsin \left(1-\frac{\delta}{A}\right)\right]
$$

\section{Effective cutting length $\left(L_{s}\right)$}

The effective cutting length $L_{s}$ is the distance one abrasive particle travels during the effective time $(\Delta t)$ from time $t_{l}$ to time $t_{3}$. To calculate the effective length, the integral of the abrasive particle's velocity $\left(V_{p}\right)$ is taken over the range from $t_{1}$ to $t_{3}$ as follow: 


$$
\begin{aligned}
& L_{s}=\int_{t_{1}}^{t_{3}} \sqrt{V_{p} \cdot V_{p}} d t \\
& L_{s}=\int_{t_{1}}^{t_{3}} \sqrt{X^{\prime 2}+Y^{\prime 2}+Z^{\prime 2}} d t \\
& L_{s} \int_{t_{1}}^{t_{3}} \sqrt{\begin{array}{l}
R^{2} \cdot \omega_{r}^{2} \cos ^{2}\left(\omega_{r} t\right)+ \\
R^{2} \cdot \omega_{r}^{2} \sin ^{2}\left(\omega_{r} t\right)+d \\
\left(\omega_{u} A \cos \left(\omega_{u} t\right)+b\right)^{2}
\end{array}}
\end{aligned}
$$

The ultrasonic superimposed term $\omega_{u} A \cos \left(\omega_{u} t\right)$ is not included in calculating $L_{s}$ in the $\mathrm{Z}$-axis because $A<<R$. That is only the $Z=b t$ component where $Z^{\prime}=b$.

$$
\begin{aligned}
& L_{s}=\int_{t_{1}}^{t_{3}} \sqrt{R^{2} \cdot \omega_{r}^{2}+b^{2}} d t \\
& L_{s}=\sqrt{R^{2} \cdot \omega_{r}^{2}+b^{2}} \Delta t
\end{aligned}
$$

However, $b^{2}<<R^{2} \cdot \omega_{r}{ }^{2}$ and $L_{s}$ simply becomes (Figure 7):

$$
L_{s}=R \cdot \omega_{r} \Delta t
$$

where: $R=\frac{D_{o}+D_{i}}{4} ; \quad \omega_{r}=\frac{2 \pi S}{60}$

$$
\begin{gathered}
L_{s}=\left(\frac{\pi S\left(D_{o}+D_{i}\right)}{120}\right) \Delta t \\
L_{s}=\left(\frac{\pi S\left(D_{o}+D_{i}\right)}{120}\right) \frac{1}{\pi f_{u}}\left[\frac{\pi}{2}-\arcsin \left(1-\frac{\delta}{A}\right)\right] \\
L_{S}=\left(\frac{S\left(D_{o}+D_{i}\right)}{120 f_{u}}\right)\left[\frac{\pi}{2}-\arcsin \left(1-\frac{\delta}{A}\right)\right]
\end{gathered}
$$

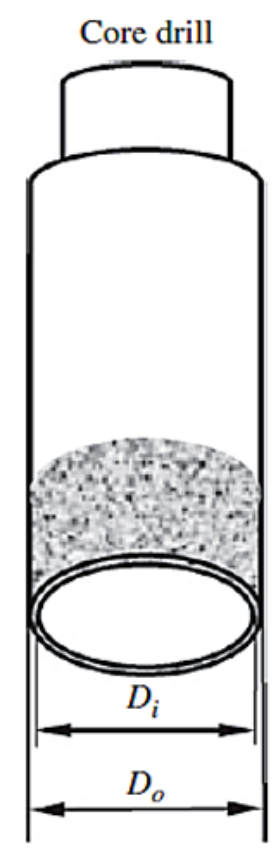

Figure 7. Core drill schematic

\section{Helix path pitch $(b)$}

The pitch value is the direct rate of penetration of the process. In one revolution a depth of the value of $h$ is reached as shown in (Figure 8). Therefore, the overall rate of penetration is expression is:

$$
\begin{aligned}
& R O P\left[\frac{m m}{s e c}\right]=h\left[\frac{m m}{r e v}\right] \mathrm{f}_{r}\left[\frac{r e v}{s e c}\right] \\
& R O P=h \mathrm{f}_{r} \\
& h=(b d t) \\
& h=\left(b \frac{2 \pi}{\omega_{r}}\right) ; \quad \omega_{r}=2 \pi \mathrm{f}_{r} \\
& R O P=b
\end{aligned}
$$

This result could also be directly observed in the particle velocity given equation.
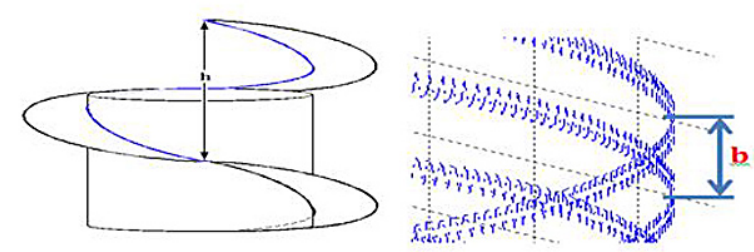

Figure 8. Drill bit helix path

\section{Maximum depth $(\delta)$}

Indentation fracture technique is used in this drilling process for what it has to offer particularly when it is applied to brittle materials. Pointindentation approach generates high stress intensity region applying shear and hydrostatic compression producing irreversible deformation on the specimen. It is a stable fracture processes that allows the examination of its effect as it apply to brittle solids. For the same reasons the point-indentation techniques are used for hardness testing such as Vickers and Knoop tests as discussed by Lawn [10]. Additional details on the point-indentation microfracture patterns in brittle solids are addressed in the following sections providing a clearer picture of the fracture mechanics beneath the point-indentation zone.

As discussed, $\delta$ is the maximum depth one abrasive particle, an indenter, penetrates into the workpiece in one ultrasonic cycle. It occurs at the maximum downward amplitude $(A)$ of the ultrasonic.

To determine $(\delta)$, the stress analysis of an indenter that is well established in the literature is addressed in this section with the focus on a sharp indenter as the type of indentation to accurately represent the abrasive particles' octahedron shape. At this point, it is important to address the development of the indentation fracture mechanics. 


\section{SHARP INDENTER FRACTURE MECHANICS}

Utilizing the hardness test to provide a systematic description of the crack pattern of the impression of the sharp intenders is fundamentally related to a great diversity of the patterns generated due to minor variations in the test system. Variations include the indenter shape, testing environment, load rate, etc. However, the major features of the fracture behavior remained general and provided the basis of the model of Lawn [10].

As the starting flaw's probable location is defined, which gradually starting a crack, one can make use of the tensile stresses maxima at the workpiece surface and contact axis for the Boussinesq field addressed earlier in this section. It is reasonable to predict the crack will tend to initiate at one of those favored locations where the stresses exceeds a critical tensile stress.

Defining the indentation fracture geometry makes it possible to quantify the crack growth in terms of the important system variables, particularly the applied load $(P)$ and the crack dimensions (a) (Figure 9). Linear fracture mechanics provides the mathematical basis for the evaluation of the mechanical-energy release rate function $(G=G(P, a))$ or other stress intensity factor equivalent function that is appropriate to a given crack configuration. However, there is no exact solution for the complex geometries present in the indentation problems and some approximations had to be made in the analysis as discussed by Lawn [10].

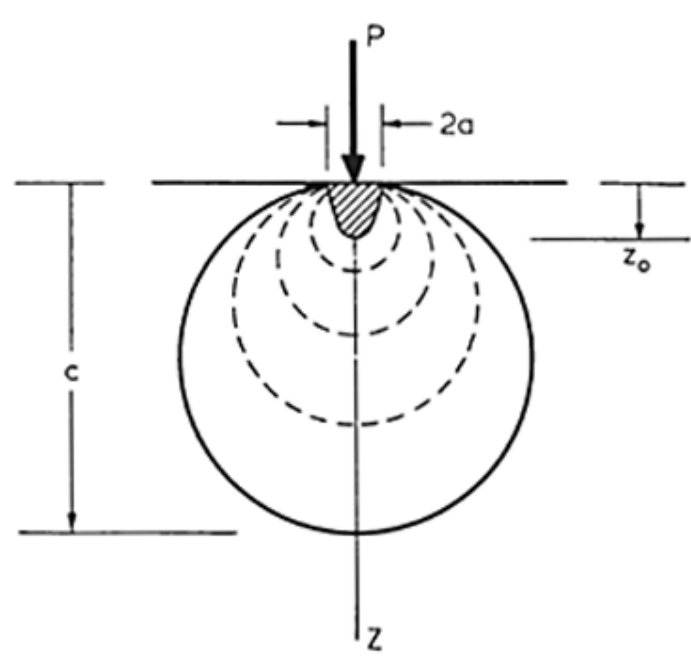

Figure 9. Parameters of the median vent configuration. Broken lines represent stress contours, heavy line represents crack profile, and shading represents inelastic deformation zone
Now it is essential to determine whether or not the value of the energy release rate $(G)$ is sufficient to propagate the crack based on a fracture criterion. It is not adequate to assume crack propagation based on the maximum tensile stress exceeding the critical level alone. Therefore, generally two basic crack propagation conditions were distinguished. The first condition is equilibrium: on an atomic level, a brittle crack grows as the cohesive bonds across the crack plane rupture and create two surfaces. The condition of the bond rupture process is assumed to operate under thermodynamics equilibrium (Griffith) [8].

$$
G=2 \Gamma
$$

Where $\Gamma$ the second condition is kinetic: the bond rupture process is a sequence of discrete events where an energy barrier to crack motion exists at the atomic level. This behavior is expressed in an atomic periodicity in the term $(\Gamma)$ and the crack may grow in a rate-dependent manner by thermal fluctuations over the barrier as discussed by Lawn [10]. Finally, the crack may propagate according to the kinetic equation:

$$
v_{c}=v_{c}(G)
$$

Where $v_{c}(G)$ is the crack velocity function appropriate to the system under consideration.

\section{Maximum depth $(\delta)$ in terms of materials hardness}

Considering the Vickers hardness test (Figure 10 and Figure 11), the maximum depth achieved by one abrasive particle can be estimated.

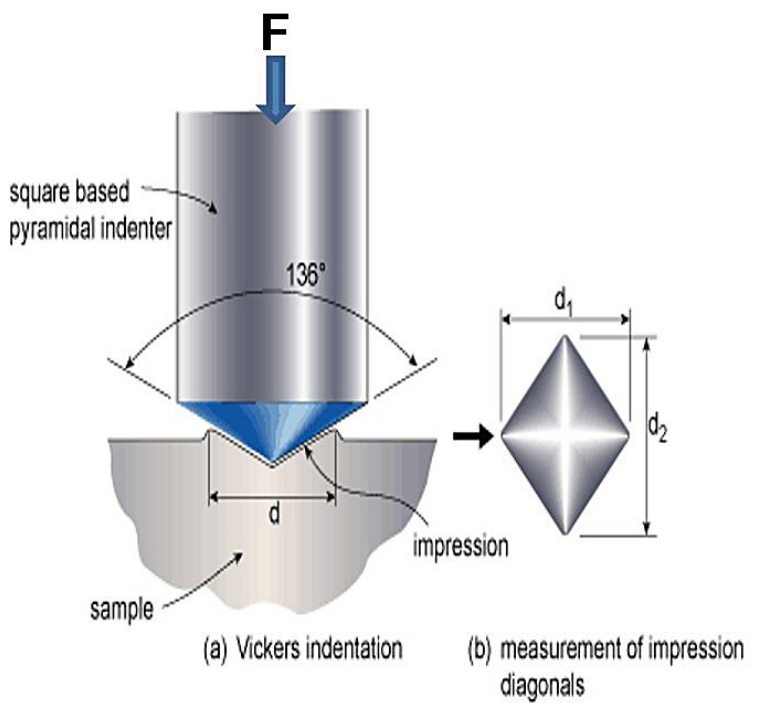

Figure 10. Vickers hardness test $F$ - applied force on one abrasive particle, $d_{1,2}$ - indentation diagonal average length. 

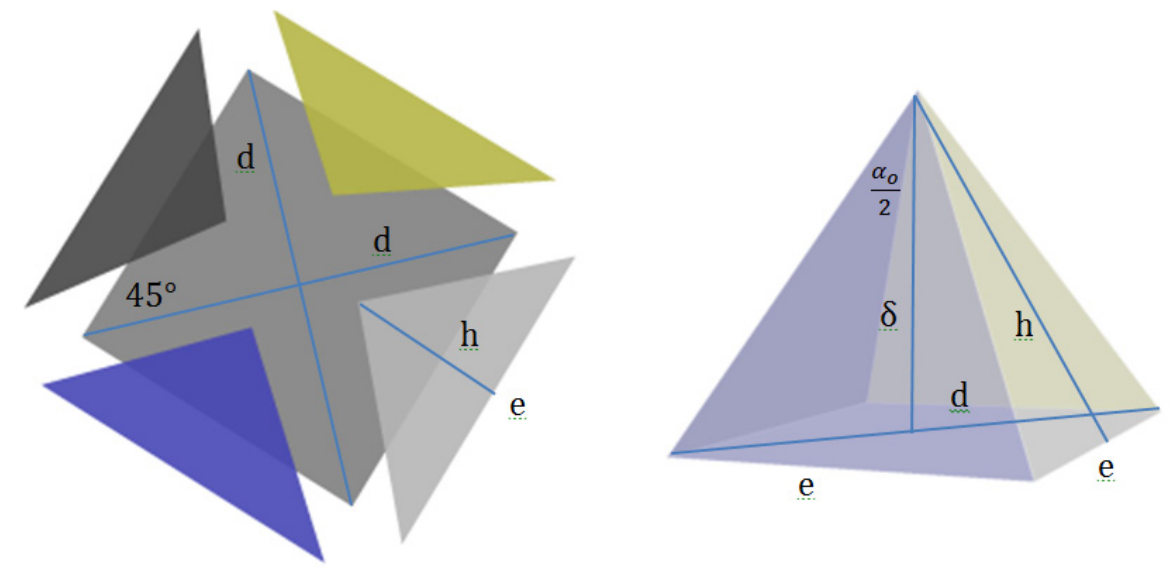

Figure 11. Vickers hardness indentation shape formed by indenter tip

The Vickers hardness indentation area $\left(A_{s}\right)$ consists of four equal triangles with base length of (e) and a height, slanted height, of ( $h$ ) (Figure 11).

$$
A_{s}=\left(2 \tan \left(\frac{\alpha_{o}}{2}\right) \sqrt{\left[\tan \left(\frac{\alpha_{o}}{2}\right)\right]^{2}+2}\right) \delta^{2}
$$

Vickers hardness is defined as the ratio of the applied force $\left(F_{n}\right)$ to the indented area.

$$
H_{v}=\frac{\text { Applied Force }}{\text { Indented Area }}=\frac{F_{n}}{A_{s}}
$$

Substituting for the expression of $A_{s}$ and solving for $A_{s}$ in terms of $F_{n}$ and $H_{v}$ gives:

$A_{s}=\frac{F_{n}}{H_{v}}=\left(2 \tan \left(\frac{\alpha_{o}}{2}\right) \sqrt{\left[\tan \left(\frac{\alpha_{o}}{2}\right)\right]^{2}+2}\right) \delta^{2}$

Finally, solving for $\delta$,

$$
\delta=\left(\frac{F_{n}}{2 \tan \left(\frac{\alpha_{o}}{2}\right) \sqrt{\left[\tan \left(\frac{\alpha_{o}}{2}\right)\right]^{2}+2} H_{v}}\right)^{1 / 2}
$$

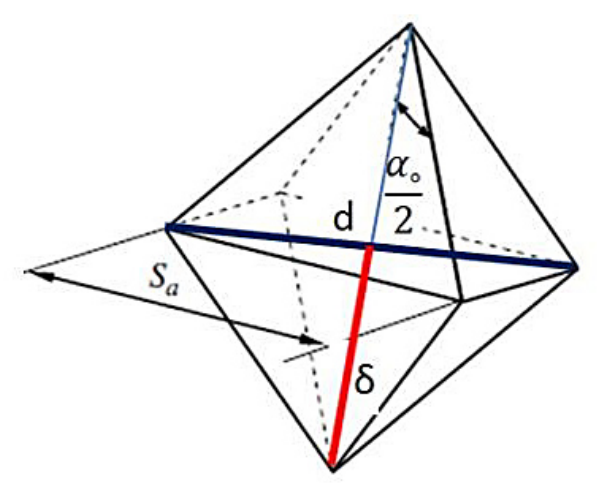

Figure 12. Abrasive particle octahedron shape showing relevant dimensions
The relationship between WOB/cutting force on the workpiece $(F)$ and force on one abrasive particle $\left(F_{n}\right)$

To establish the relationship between the cutting force $(F)$ on the entire drill bit and the force exerted on one abrasive particle $\left(F_{n}\right)$, we will take in consideration that the particle is a rigid body and impulses during one ultrasonic cycle are the same as discussed by Liu [12].

Let

$F_{m} \equiv$ maximum impact force between core drill and workpiece

$F_{n} \equiv$ force applied on one abrasive particle

$F^{n} \equiv$ force measured during the experiment/

force applied $=$ WOB

$I_{l}, I_{2} \equiv$ impulse during one ultrasonic cycle

The impulse of one abrasive particle as a rigid body in terms of maximum impact force $F_{m}$ during one ultrasonic vibration can be calculated as:

$$
I_{1}=\int_{c y c l e} F_{m} d t \approx F_{m} \Delta t
$$

Impulse in terms of total cutting force $\mathrm{F}$ can be calculated as:

$$
\begin{aligned}
I_{2} & =\frac{1}{f_{u}} F \\
F_{m} & =N_{a} F_{n}
\end{aligned}
$$

and

By equating impulses and solving for the cutting force $\mathrm{F}$ :

$$
\begin{aligned}
& F=f_{u} F_{m} \Delta t \\
& F=f_{u} F_{n} N_{a}\left(\frac{1}{\pi f_{u}}\left[\frac{\pi}{2}-\arcsin \left(1-\frac{\delta}{A}\right)\right]\right) \\
& F=F_{n}\left(\frac{N_{a}}{\pi}\left[\frac{\pi}{2}-\arcsin \left(1-\frac{\delta}{A}\right)\right]\right)
\end{aligned}
$$

Finally, the force exerted on one abrasive particle $\left(F_{n}\right)$ in terms of cutting force on the workpiece $(F)$ is: 


$$
F_{n}=\frac{\pi \boldsymbol{F}}{N_{a}\left[\frac{\pi}{2}-\arcsin \left(1-\frac{\delta}{A}\right)\right]}
$$

\section{Number of abrasive particles $\left(N_{a}\right)$}

The number of active abrasive particles taking part in cutting on the drill bit cross section depends upon the abrasive concentration $\left(C_{q}\right)$. The usual measure for this concentration is defined in terms of abrasives weight. If $C_{a}=100$, then there is $0.88 \times 10^{-3} \mathrm{~g} / \mathrm{mm}^{3}$ of abrasive in matrix material as discussed by Liu [12]. Assuming uniform particles distribution in the abrasive portion of the core drill, the number of abrasive particle $\left(\mathrm{N}_{\mathrm{a}}\right)$ can be calculated as:

$$
N_{a}=\left[\left(\frac{0.88 \times 10^{-3} g}{m m^{3}}\right)\left(\frac{C_{a}}{100}\right) \frac{1}{\left(\frac{\sqrt{2}}{3} S_{a}^{3}\right) \rho}\right]^{2 / 3} A_{o}
$$

where: $\rho$ - is the abrasive particle mass density.

Octahedron's volume $=\frac{\sqrt{2}}{3} S_{a}^{3}$

Let

$$
\begin{aligned}
& C_{1}=\left(\frac{3 \times 0.88 \times 10^{-3}}{100 \sqrt{2} \rho}\right)^{2 / 3} \\
& N_{a}=C_{1}\left(\frac{C_{a}^{2 / 3} A_{o}}{S_{a}^{2}}\right)
\end{aligned}
$$

where: $S_{a}$ - abrasive particle length (equal for 12 sides of the octahedron shape), $C_{a}-$ abrasive particles concentration, $A_{o}-$ area of core drill end face / cross section,

$C_{1}-$ dimensionless constant ( $\rho$ is the density of abrasive material, $\mathrm{g} / \mathrm{mm}^{3}, \rho=$ $3.52 \times 10^{3} \mathrm{~g} / \mathrm{mm}^{3}$ for diamond).

\section{Material removal rate for one abrasive particle $\left(M R R_{p}\right)$}

To calculate the material removal rate for one abrasive particle, first we define the fracture zone at the indenter/abrasive particle cutting point or tip. Upon exerting force on the abrasive particle, a fracture zone is formed that consists of a plastic zone, median crack and lateral crack. The material removed is primarily influenced by the lateral crack that has a length of $\left(C_{L}\right)$ and a height of $\left(C_{h}\right)$ as shown in Figure 13.

The material removal volume is based on the facture zone developed using hardness tests. To further understand the fracture zone, one of the

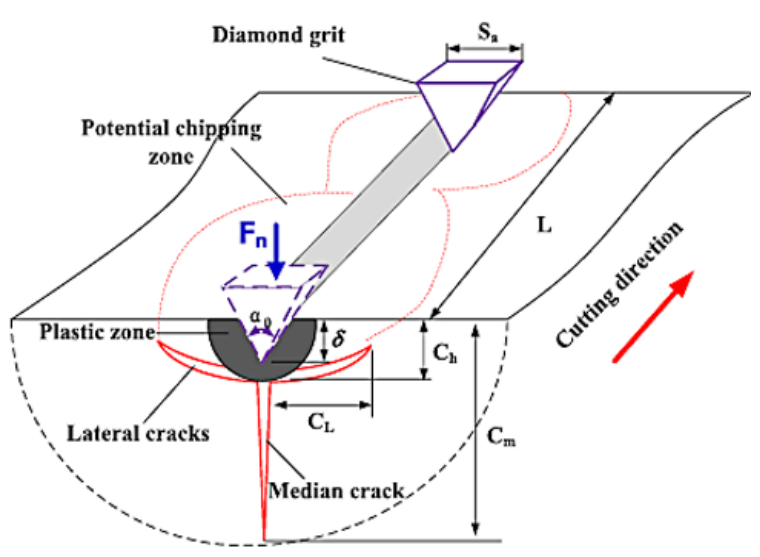

Figure 13. Schematic diagram of material removal in brittle fracture mode induced by the abrasive particle process, Zhang [15]

hardness tests applying an indenter is The Knoop hardness test that is presented for clarity. It is a micro-hardness test and it is a particularly used to test brittle materials that makes a small indentation that is used for testing purposes. The Knoop indenter is an octahedron diamond shaped particle that is pressed against a polished surface of the tested materials with a load of $100 \mathrm{~N}$ and applied for a period of time. A microscope is used to measure the resulting indentation from Knoop and Vickers hardness tests shown in in the figure below and discussed by Lawn [10].

To calculate the material removal rate for one particle $\left(M R R_{p}\right)$, first we calculate a theoretical volume $\left(V_{o}\right)$ which will then be compared with actual volume $(V)$ of the fracture zone. As the abrasive particle comes in contact with the workpiece and start cutting at $t_{l}$, the cutting depth increases from zero to the maximum depth $\delta$ at $t_{2}$ and then decreases again to zero at $t_{3}$ while moving the distance $L_{s}$ on the workpiece surface, see Figure 15.

As a result to the aforementioned cutting process, the lateral crack length $C_{L}$ and height $C_{h}$ will increase and decrease accordingly forming the fracture zone volume. This volume is simplified to two tetrahedron volume of $\mathrm{ABCD}$ as shown in Figure 15 as follow as discussed by Liu [11].

$$
V_{o}=2 V_{A B C D}=\frac{1}{3} L_{S} C_{L} C_{h}
$$

Abrasive particles' theoretical volume $\left(V_{o}\right)$ of the fracture zone may overlap and interrelations between it and the actual voluem $(V)$ is expressed through the volume proportionality $(K)$ as follow:

$$
V=K V_{o}=\frac{K}{3} L_{s} C_{L} C_{h}
$$




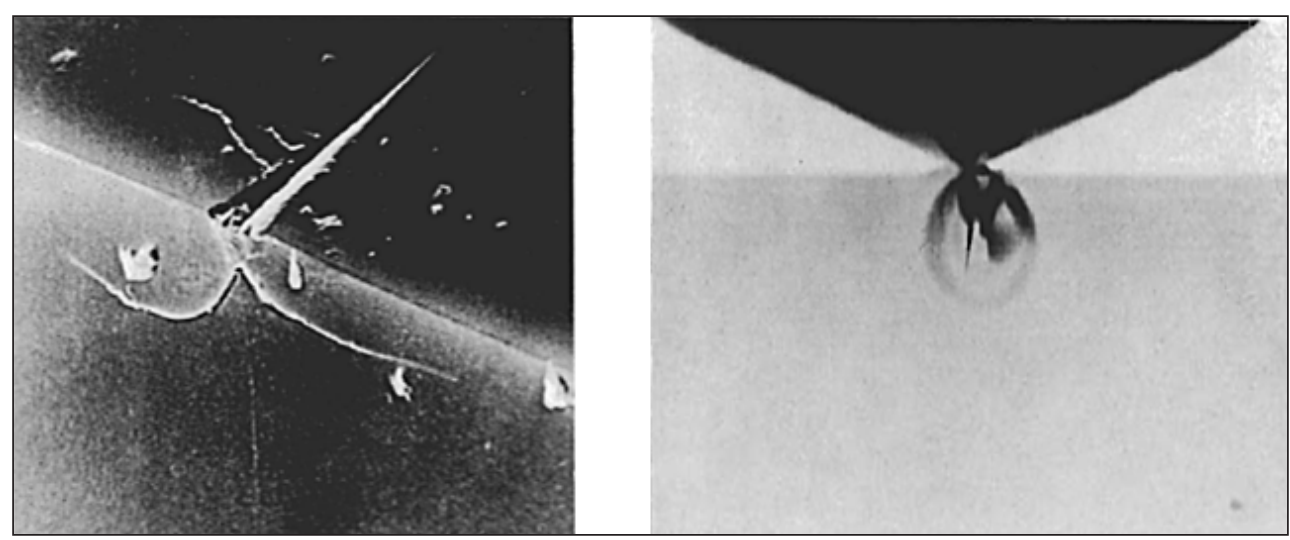

Figure 14. Scanning electron micrograph of Knoop impression quartz (000I) surface. Section shows inelastic deformation zone immediately below surface impression, and associated vent pattern. Indenter load $2 \mathrm{~N}$. Width of filed $100 \mu \mathrm{m}$ (left) and In situ photograph of Vickers indentation in soda-lime glass taken in transmitted light with an indenter load of $250 \mathrm{~N}$ and width of field of $11 \mathrm{~mm}$ (right) [9]

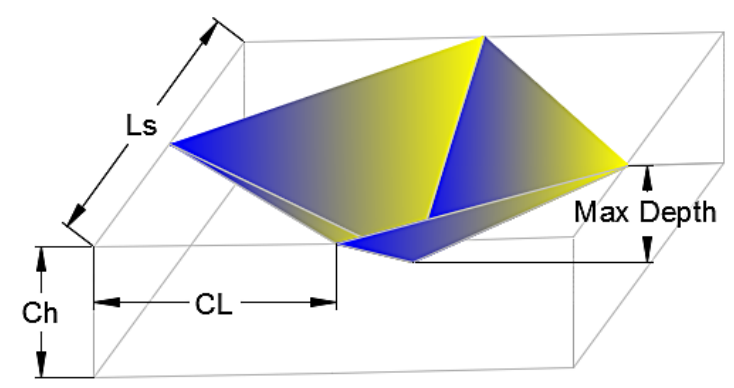

Figure 15. Fracture zone theoretical volume calculation (Vo)

where: $K$-constant proportionality due to interrelations among abrasive particles, Liu [11]

The particle material removal rate $\left(M R R_{a}\right)$ is the product of the fracture zone actual volume times the ultrasonic frequency. By substituting the values of $L_{s}$ in actual volume $(V)$ above, the particle material removal rate could be calculated as:

$$
\begin{gathered}
M M R_{a}=f_{u} \cdot V=\frac{K}{3}\left(\frac{S\left(D_{o}+D_{i}\right)}{120}\right) . \\
\cdot\left[\frac{\pi}{2}-\arcsin \left(1-\frac{\delta}{A}\right)\right] C_{L} C_{h}
\end{gathered}
$$

\section{Material removal rate for core drill $\left(M R R_{d}\right)$}

The material removal rate for the core drill bit is calculated based on the product of the material removal rate of one abrasive particle times the number of abrasive particles takes part in cutting as:

$$
M M R_{d}=N_{a} \cdot M R R_{a}
$$

Substituting for $N_{a}$ and $M R R_{a}$

$$
\begin{gathered}
M M R_{d}=\frac{K C_{1}}{360}\left(\frac{C_{a}^{2 / 3} A_{o}\left(D_{o}+D_{i}\right)}{S_{a}^{2}}\right) \\
\cdot(S)\left[\frac{\pi}{2}-\arcsin \left(1-\frac{\delta}{A}\right)\right] C_{L} C_{h}
\end{gathered}
$$

\section{Lateral cracks length $\left(C_{L}\right)$ and depth $\left(C_{h}\right)$}

The brittle fracture mechanism of materials has been investigated in previous literature using indentation fracture mechanics as discussed by Lawn [9, 10], Ostojic [13] and Marshall [12]. As shown in Figure 13, the indentation of an abrasive particle generates cracks in brittle materials. The lateral crack length $C_{L}$ and lateral crack depth $C_{h}$ were determined by Marshall [12] to be:

$$
\begin{aligned}
& C_{L}=C_{2}\left(\cot \frac{\alpha_{o}}{2}\right)^{5 / 12}\left(\frac{E^{3 / 4}}{H_{v} K_{I C}\left(1-v^{2}\right)^{1 / 2}}\right)^{1 / 2}\left(F_{n}\right)^{5 / 8} \\
& C_{h}=C_{2}\left(\cot \frac{\alpha_{o}}{2}\right)^{1 / 3}\left(\frac{E^{1 / 2}}{H_{v}}\right)\left(F_{n}\right)^{1 / 2}
\end{aligned}
$$

Substitute for $F_{n}$

$$
\begin{gathered}
C_{L} C_{h}=\frac{C_{2}{ }^{2}}{\left(\tan \frac{\alpha_{o}}{2}\right)^{3 / 4}}\left(\frac{E^{7 / 8}}{H_{v}^{3 / 2} K_{I C}^{1 / 2}\left(1-v^{2}\right)^{1 / 4}}\right) \\
\left(\frac{\pi \boldsymbol{F}}{N_{a}\left[\frac{\pi}{2}-\arcsin \left(1-\frac{\delta}{A}\right)\right]}\right)^{9 / 8}
\end{gathered}
$$

where: $E$-workpiece Young's modulus, $K_{I C}$ - workpiece fracture toughness, 
$v$ - workpiece Poisson's ratio,

$C_{2}=0.226$ dimensionless constant that is dependent on the material/indenter system, Lawn [9].

\section{Rate of penetration (ROP)}

It was previously shown that

$$
M M R_{d}=N_{a} \cdot M R R_{a}
$$

Also, $M R R_{d}$ could be expressed in terms of feed rate $(b[\mathrm{~mm} / \mathrm{s}])$ and the area of drill core end face $\left(A_{o}\right)$ as:

$$
M M R_{d}=b \cdot A_{o}
$$

Since $b=R O P$ and $A_{o}=\frac{\pi\left(D_{o}^{2}-D_{i}^{2}\right)}{4}$

By equating $M R R_{d}$ equations the following result is obtained:

$$
M M R_{d}=N_{a} \cdot M M R_{d}=b \cdot A_{o}
$$

or

$$
\begin{aligned}
& N_{a} M R R_{a}=R O P A_{o} \\
& R O P=\frac{N_{a}}{A_{o}} M R R_{a}
\end{aligned}
$$

Substituting for the values of $N_{a}, A_{o}$, and $M R R_{a}$, we obtain the following equation for the rate of penetration $R O P$ :

$$
\begin{gathered}
R O P=\frac{N_{a}}{A_{o}} M R R_{a} \\
R O P=\frac{N_{a}}{A_{o}} \frac{K}{3}\left(\frac{S\left(D_{o}+D_{i}\right)}{120}\right)\left[\frac{\pi}{2}-\arcsin \left(1-\frac{\delta}{A}\right)\right] C_{L} C_{h} \\
C_{L} C_{h}=\frac{C_{2}^{2}}{\left(\tan \frac{\alpha_{o}}{2}\right)^{3 / 4}\left(\frac{E^{7 / 8}}{H_{v}^{3 / 2} K_{I C}^{1 / 2}\left(1-v^{2}\right)^{1 / 4}}\right)} \\
\left(\frac{\pi \boldsymbol{F}}{N_{a}\left[\frac{\pi}{2}-\arcsin \left(1-\frac{\delta}{A}\right)\right]}\right)^{9 / 8}
\end{gathered}
$$

To simplify the derivation, let the material properties in $C_{L} C_{h}$ equation $=Q$ as follow:

$$
Q=\left(\frac{E^{7 / 8}}{H_{v}^{3 / 2} K_{I C}^{1 / 2}\left(1-v^{2}\right)^{1 / 4}}\right)
$$

then

$$
\begin{aligned}
R O P= & \left(\frac{K C_{2}{ }^{2} 4^{9 / 8}}{360 C_{1}^{1 / 8}}\right)\left(\frac{S_{a}^{1 / 4}\left(D_{o}+D_{i}\right)}{C_{a}^{1 / 12}\left(D_{o}^{2}-D_{i}^{2}\right)^{9 / 8}\left(\tan \frac{\alpha_{o}}{2}\right)^{3 / 4}}\right) \\
& (Q)\left(\frac{S \mathrm{~F}^{9 / 8}}{\left[\frac{\pi}{2}-\arcsin \left(1-\frac{\delta}{A}\right)\right]^{1 / 8}}\right)
\end{aligned}
$$

Let $D_{\text {avg }}=\frac{D_{o}+D_{i}}{2}$

then $D_{o}+D_{i}=2 D_{\text {avg }}$

Also, $D_{o}^{2}-D_{i}^{2}=\left(D_{o}+D_{i}\right)\left(D_{o}-D_{i}\right)$

Let the thickness $t=\frac{\left(D_{o}-D_{i}\right)}{2}$

$$
\begin{aligned}
& D_{o}^{2}-D_{i}^{2}=\left(2 D_{\text {avg }}\right)(2 t) \\
& D_{o}^{2}-D_{i}^{2}=4 t D_{\text {avg }}
\end{aligned}
$$

Substituting the values of $\left(D_{o}+D_{i}\right)$ and $\left(D_{o}^{2}\right.$ $\left.-D_{i}^{2}\right)$ in the above equation yield the final ROP expression:

$$
\begin{aligned}
R O P= & \left(\frac{K C_{2}^{2} 4^{9 / 8}}{360 C_{1}^{1 / 8}}\right)\left(\frac{S_{a}^{1 / 4} 2 D_{\text {avg }}}{C_{a}^{1 / 12}\left(4 t D_{\text {avg }}\right)^{9 / 8}\left(\tan \frac{\alpha_{o}}{2}\right)^{3 / 4}}\right) \\
& \left(\frac{S \mathrm{~F}^{9 / 8}}{\left[\frac{\pi}{2}-\arcsin \left(1-\frac{\delta}{A}\right)\right]^{1 / 8}}\right)(Q)
\end{aligned}
$$

Substitute for the material properties $Q$ and finally the ROP equation is:

$$
R O P=G_{1}\left(\frac{s_{a}^{1 / 4}}{C_{a}^{1 / 12(t)^{9 / 8}\left(D_{\text {avg }}\right)^{1 / 8}\left(\tan \frac{\alpha_{o}}{2}\right)^{3 / 4}}}\right) x
$$

Drill bit design

$$
\left(\frac{S(\boldsymbol{F})^{9 / 8}}{\left[\frac{\pi}{2}-\arcsin \left(1-\frac{\delta}{A}\right)\right]^{1 / 8}}\right) \boldsymbol{x}
$$

Process design

$$
\left(\frac{E^{7 / 8}}{H_{v}^{3 / 2} K_{I C}^{1 / 2}\left(1-v^{2}\right)^{1 / 4}}\right)
$$

Material properties

where: $G_{1}=\frac{K C_{2}{ }^{2}}{180 C_{1}{ }^{1 / 8}}$

The above ROP expression can be approximated to even a simpler form by recognizing that that $\left[\frac{\pi}{2}-\arcsin \left(1-\frac{\delta}{A}\right)\right]^{1 / 8} \approx 1$ (Figures 16 and 17). As the ultrasonic amplitude $A$ changes and the corresponding maximum depth $\delta$ also changes the data generated from experiments as well as the mathematical model supports this results.

Also, the semi-angle is constant in this study and it is roughly $\alpha_{o}=120^{\circ}$, and the drill bit thickness $t=1 \mathrm{~mm}$.

Then, the expression $\left(\tan \frac{\alpha_{o}}{2}\right)^{3 / 4}=1.51$, 


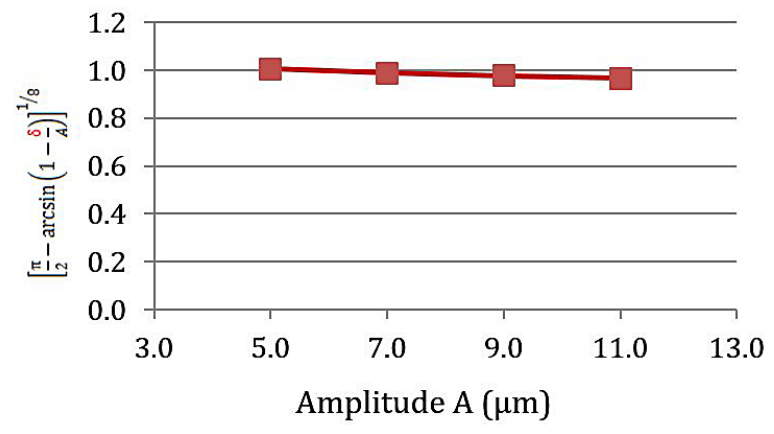

Figure 16. The expression $\left[\frac{\pi}{2}-\arcsin \left(1-\frac{\delta}{A}\right)\right]^{1 / 8} \approx 1$

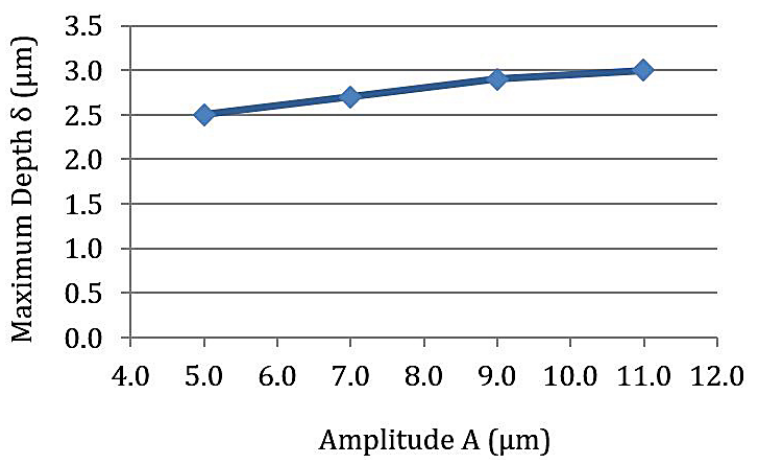

Figure 17. Ultrasonic amplitude vs. max. depth

and $(t)^{9 / 8}=0.000422$

$$
G_{2}=\frac{G_{1}}{(1.51)(0.000422)}=\frac{K C_{2}{ }^{2}}{0.11 C_{1}{ }^{1 / 8}}
$$

Finally,

$$
\begin{aligned}
& R O P=G_{2}(W O B)^{9 / 8}\left(\frac{S S_{a}^{1 / 4}}{C_{a}^{1 / 12}\left(D_{a v g}\right)^{1 / 8}}\right) \\
& \left(\frac{E^{7 / 8}}{H_{v}^{3 / 2} K_{I C}^{1 / 2}\left(1-v^{2}\right)^{1 / 4}}\right)
\end{aligned}
$$

The performance of a number of the key parameter in the developed rate of penetration mathematical model is predicted in this chap- ter. In the efforts of validating the mathematical model, the predicted results are compared to experimental results and presented in following section.

\section{EXPERIMENT DESIGN}

The rotary-ultrasonic drill utilizes the dual action of rotational and axial motion of the bit in the core drilling process. The ultrasonic drill uses a power supply that converts conventional line voltage $(60 \mathrm{~Hz})$ to a high frequency electrical energy of $20 \mathrm{kHz}$ AC output. A piezoelectric converter receives this high frequency electrical signal and changes it into a mechanical motion. The ultrasonic mechanical motion gets amplified and transmitted to the horn and cutting tool. The resulting motion is a vertical oscillation of the cutting tool acting predominantly on the workpiece. The motor located on top of the ultrasonic spindle rotates it in the plane where the rotation speed can be controlled. The final cutting action is takes a helical path as the drill bit rotates in the plane due to the rotary motion and moves down at ROP and it also oscillates vertically due to the ultrasonic vibration (Figure 18).

The rate of penetration depends on a number of parameters associated with the drill bit design, the material being drilled, and the overall process variables such as rotation speed, ultrasonic amplitude and applied force. For ease of this discussion, ROP equation is restated here, with the various parameters grouped according to type. The first set of parameters contains the drill bit design variables; the second contains the process variables, while the third contain he material parameters.

The following equation was developed determining the effect of the input variables on the ROP performance:

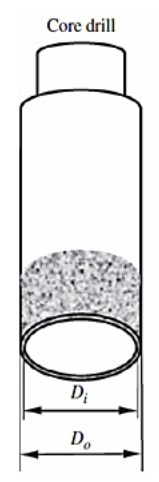

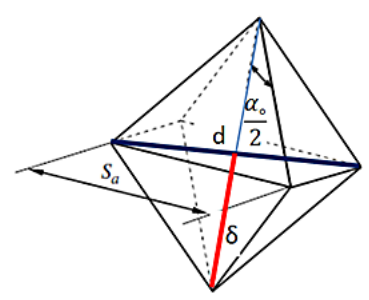

Abrasive particle variables

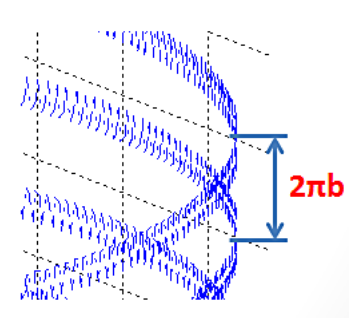

Helix path pitch "b"

Figure 18. Drill, abrasive particle and ultrasonic wave parameters 
$R O P=G_{1}\left(\frac{S_{a}^{1 / 4}}{C_{a}^{1 / 12}(t)^{9 / 8}\left(D_{\text {avg }}\right)^{1 / 8}\left(\tan \frac{\alpha_{o}}{2}\right)^{3 / 4}}\right) X$

$\left(\frac{S(\boldsymbol{F})^{9 / 8}}{\left[\frac{\pi}{2}-\arcsin \left(1-\frac{\delta}{A}\right)\right]^{1 / 8}}\right)\left(\frac{E^{7 / 8}}{H_{v}^{3 / 2} K_{I C}^{1 / 2}\left(1-v^{2}\right)^{1 / 4}}\right)$

where: $G_{1}=\frac{K C_{2}{ }^{2}}{180 C_{1}{ }^{1 / 8}}$

According to this model, there are twelve parameters that affect the rate of penetration: five associated with the drill bit design, four with the material being drilled and three process parameters (recall that $\delta$ and $F$ are related as shown in previous equations).

\section{Experiments parameters}

In order to examine the validity of this model, a series of core drilling tests were performed for three types of rock. All of the process parameters and all of the bit design parameters except for $(t)$ and $\left(a_{\mathrm{o}}\right)$ were varied. However, it is important to note that the rotary ultrasonic system used for these tests controlled ROP and measured $F$. Table 2 summarizes the values used for each parameter.

Rock types were chosen to represent a variety of strength. The three types of rocks were chosen based on their strength where the travertine (sedimentary rock type/limestone) has least strength, marble is average (metamorphic rock type), and basalt (igneous rock type) is the strongest according to data provided in the literature (Table 3).
Material properties needed for the developed mathematical model are elastic modulus (E) and Poisson's ratio $(v)$ that are determined form uniaxial compression strength test (UCS). Fracture toughness $\left(\mathrm{K}_{\mathrm{IC}}\right)$ and Vickers hardness $\left(\mathrm{H}_{\mathrm{V}}\right)$ tests were also conducted where the average value of three tests were determined for each property for each type of rock. The dimensions of the samples used for each test are given (Table 4).

The material properties have a great effect on the rate of penetration performance. This is clearly evidenced in the developed mathematical model involving elastic modulus (E), fracture toughness $\left(\mathrm{K}_{\mathrm{IC}}\right)$, Vickers hardness $\left(\mathrm{H}_{\mathrm{v}}\right)$, and Poisson's ratio $(v)$. Three different types of rocks are investigated in this research that covers wide range of rock strength, travertine as a soft rock, marble as a medium strength rock, and basalt as a hard rock.

\section{MATERIAL PROPERTY TESTS}

\section{Uniaxial compression test}

The material elastic modulus and Poisson's ratio were obtained by conducting the uniaxial compression test and calculated based on the stress / strain curve and axial and lateral strain curves respectively. ASTM standard (701214) was followed and the prepared specimens had length to diameter ratios between 2.0:1 and 2.5:1". The rock specimen's diameter should be about 10 times the size of the largest mineral grain (ASTM D4543). Each cylinder specimen for the three types of rocks was either 1" in diameter or larger. Parallel surfaces of both ends of

Table 2. Experiments value range for each drill bit design and process parameters

\begin{tabular}{|c|c|c|c|c|c|c|}
\hline \multirow{2}{*}{ Sets } & \multicolumn{3}{|c|}{ Drilling process parameters } & \multicolumn{3}{c|}{ Drill bit design parameters } \\
\cline { 2 - 7 } & $\begin{array}{c}\text { Spindle speed } \\
\mathrm{S}(\mathrm{rpm})\end{array}$ & $\begin{array}{c}\text { Feed rate } \\
b(\mathrm{~mm} / \mathrm{sec})\end{array}$ & $\begin{array}{c}\text { Ultrasonic } \\
\text { amplitude } A(\mu \mathrm{rn})\end{array}$ & $\begin{array}{c}\text { Abrasive size } \\
S_{a}(\mathrm{~mm})\end{array}$ & $\begin{array}{c}\text { Abrasive } \\
\text { concentration } C_{a}\end{array}$ & $\begin{array}{c}\text { Average drill } \\
\text { bit size } \\
D_{\text {avg }}(\mathrm{mm})\end{array}$ \\
\hline 1 & $1500,2500,3500,4500$ & 0.3 & 7 & 0.125 & 100 & 11 \\
\hline 2 & 2500 & $0.1,0.3,0.5,0.7$ & 7 & 0.125 & 100 & 11 \\
\hline 3 & 2500 & 0.3 & 7 & 0.125 & 100 & 11 \\
\hline 4 & 2500 & 0.3 & 7 & $0.08,0.12,0.16,0.20$ & 100 & 11 \\
\hline 5 & 2500 & 0.3 & 7 & 0.125 & $50,100,150$ & 11 \\
\hline 6 & 2500 & 0.3 & 7 & 0.125 & 100 & $8,11,14$ \\
\hline 7 & 2500 & 0.3 & $5,7,9,11$ & 0.125 & 100 & 11 \\
\hline 8 & Establishing the K value for travertime & - & - & - & - \\
\hline 9 & Establishing the K value for marble & - & - & - & - & - \\
\hline 10 & \multicolumn{2}{|l|}{ Establishing the K value for basalt } & - & - & - & - \\
\hline
\end{tabular}


Table 3. Mechanical properties of rock materials

\begin{tabular}{|c|c|c|c|c|c|c|c|}
\hline Rock & $\begin{array}{l}\text { UC strength } \\
(\mathrm{MPa})\end{array}$ & $\begin{array}{c}\text { Tensile } \\
\text { strength } \\
(\mathrm{MPa})\end{array}$ & $\begin{array}{c}\text { Elastic } \\
\text { modulus } \\
(\mathrm{GPa})\end{array}$ & Poisson's ratio & $\begin{array}{c}\text { Strain at failure } \\
(\%)\end{array}$ & $\begin{array}{c}\text { Point load } \\
\text { index } \\
\text { (MPa) }\end{array}$ & $\begin{array}{c}\text { Fracture mode } \\
\text { toughness }\end{array}$ \\
\hline \multicolumn{8}{|c|}{ Igneous } \\
\hline Granite & $100-300$ & $7-25$ & $30-70$ & 0.17 & 0.25 & $5-15$ & $0.11-0.41$ \\
\hline Dolerite & $100-350$ & $7-30$ & $30-100$ & $0.10-0.20$ & 0.30 & - & $>0.41$ \\
\hline Gabbro & $150-250$ & $7-30$ & $40-100$ & $0.20-0.35$ & 0.30 & $6-15$ & $>0.41$ \\
\hline Rhyolite & $80-160$ & $5-10$ & $10-50$ & $0.20-0.40$ & - & - & - \\
\hline Andesite & $100-300$ & $5-15$ & $10-70$ & 0.20 & - & $10-15$ & - \\
\hline Basalt & $100-350$ & $10-30$ & $40-80$ & $0.10-0.20$ & 0.35 & $9-15$ & $>0.41$ \\
\hline \multicolumn{8}{|c|}{ Sedimentary } \\
\hline Conglomerate & $30-230$ & $3-10$ & $10-90$ & $0.10-0.15$ & 0.16 & - & - \\
\hline Sandstone & $20-170$ & $4-25$ & $15-50$ & 0.14 & 0.20 & $1-8$ & $0.027-0.041$ \\
\hline Shale & $5-100$ & $2-10$ & $5-30$ & 0.10 & - & - & $0.027-0.041$ \\
\hline Mudstone & $10-100$ & $5-30$ & $5-70$ & 0.15 & 0.15 & $0.1-6$ & - \\
\hline Dolomite & $20-120$ & $6-15$ & $30-70$ & 0.15 & 0.17 & - & - \\
\hline Limestone & $30-250$ & $6-25$ & $20-70$ & 0.30 & - & $3-7$ & $0.027-0.041$ \\
\hline \multicolumn{8}{|c|}{ Metamorphic } \\
\hline Gneiss & $100-250$ & $7-20$ & $30-80$ & 0.24 & 0.12 & $5-15$ & $0.11-0.41$ \\
\hline Schist & $70-150$ & $4-10$ & $5-60$ & $0.15-0.25$ & - & $5-10$ & $0.05-0.027$ \\
\hline Phylite & $5-150$ & $6-20$ & $10-85$ & 0.26 & - & - & - \\
\hline Slate & $50-180$ & $7-20$ & $20-90$ & $0.20-0.30$ & 0.35 & $1-9$ & $0.027-0.041$ \\
\hline Marble & $50-200$ & $7-20$ & $30-70$ & $0.15-0.30$ & 0.40 & $4-12$ & $0.11-0.41$ \\
\hline Quartizite & $150-300$ & $5-20$ & $50-90$ & 0.17 & 0.20 & $5-15$ & $>0.41$ \\
\hline
\end{tabular}

Table 4. Specimens dimensions and quantities for materials properties tests

\begin{tabular}{|c|c|c|c|c|}
\hline Test & Quantity & Travertine & Marble & Basalt \\
\hline & & 1" dia×2.5" & - & 2" dia $\times 4 "$ \\
\hline UCS & 3 & length & $\begin{array}{l}\text { 1" dia×2.5" } \\
\text { length }\end{array}$ & length \\
\hline $\begin{array}{l}\text { Fracture } \\
\text { toughness }\end{array}$ & 3 & $1 " \times 1 " \times 10 "$ & $1 " \times 1 " \times 10 "$ & $2 " \times 2 " \times 14 "$ \\
\hline $\begin{array}{l}\text { Vickers } \\
\text { hardness }\end{array}$ & 3 & $10 " \times 2.5 "$ & $2.5 " \times 6 "$ & $4 " \times 5 "$ \\
\hline No. of holes & - & 480 & 380 & 280 \\
\hline
\end{tabular}

the samples were ensured by conducting milling process on the three samples of each rock type.

Material property tests were conducted at the Structures Laboratory of CEE at UC Berkeley (http://www.ce.berkeley.edu/). The report summarizing test results including the following: According to ASTM Practice D4543, rock speci- mens shall be right circular cylinders. The length to diameter ratio should be from 2.0 to 2.5 with the minimum diameter of $47 \mathrm{~mm}\left(1-7 / 8^{\prime \prime}\right)$. The rock specimen's diameter should be about 10 times of the largest mineral grain. Due to limitations of the supplied raw material, the diameter of the test samples was limited to slightly less than 1 -in. Table 5 lists all rock samples made available for the material tests. The table below presents the dimensions of the samples and the length (height) to diameter ratio (Table 5) (Shakhzod Takhirov, PhD, PE, Short Report/Memo No: 2015-SLUCB-R01).

The strains were monitored by uniaxial and rosette strain gages. The main objective of the testing program was to estimate:

a) Ultimate compressive strength (D2938),

b) Poisson's ratio (D3148),

c) Young modulus (D3148).

Table 5. List of rock samples available for the material testing

\begin{tabular}{|c|c|c|c|c|c|}
\hline Specimens & Color & Rock material & Height $(\mathrm{H})$, in & Diameter $(\mathrm{D})$, in & Ratio $(\mathrm{H} / \mathrm{D})$ \\
\hline $\mathrm{Sp} 1, \mathrm{Sp} 2, \mathrm{Sp} 3$ & white & marble & 2.132 & 0.996 & 2.14 \\
\hline $\mathrm{Sp} 4.0, \mathrm{Sp} 4, \mathrm{Sp} 5$ & brown & travertine & 2.135 & 0.990 & 2.16 \\
\hline $\mathrm{Sp} 7, \mathrm{Sp} 8, \mathrm{Sp} 9$ & black & basalt & 2.140 & 0.992 & 2.16 \\
\hline
\end{tabular}


The following measurements were recorded during the tests:

a) Compression load via a load cell in the Universal Test Machine (UTM),

b) Axial strain via a longitudinal strain gage,

c) Transverse strain gage via a strain gage installed in transverse direction,

d) Displacement of the UTM's head.

The UTM was operated in force control with the load increasing at about $12 \mathrm{lb}$ per second. The uniaxial compressive strength $\left(\sigma_{u}\right)$ is determined from the failure load and specimen cross section area, $F_{\max }$, and $A$ as (ASTM D7012).

$$
\sigma_{u}=\frac{F_{\max }}{A}
$$

where: $\sigma_{u}-$ uniaxial compressive strength (MPa)

$\mathrm{F}_{\max }-$ failure load $(\mathrm{kN})$

A - cross-sectional area $\left(\mathrm{mm}^{2}\right)$

The elastic modulus is obtained from the central portion of the stress strain curve generated from the uniaxial compression test (ASTM D7012). Poisson's ratio is typically calculated from the axial and lateral strain curves generated from the uniaxial compression test (ASTM D7012).

A photo of tested specimen is presented in Figure 19 and failure modes of the test specimens of travertine, marble, and basalt are also presented in Figures 20, 21 and 22.

The average value of the two tests of each type of rock was calculated and report as shown in Table 7.

\section{Vickers hardness test}

The principle of Vickers hardness test is obtaining a hardness number that is based on a relatively small indentation made in the material

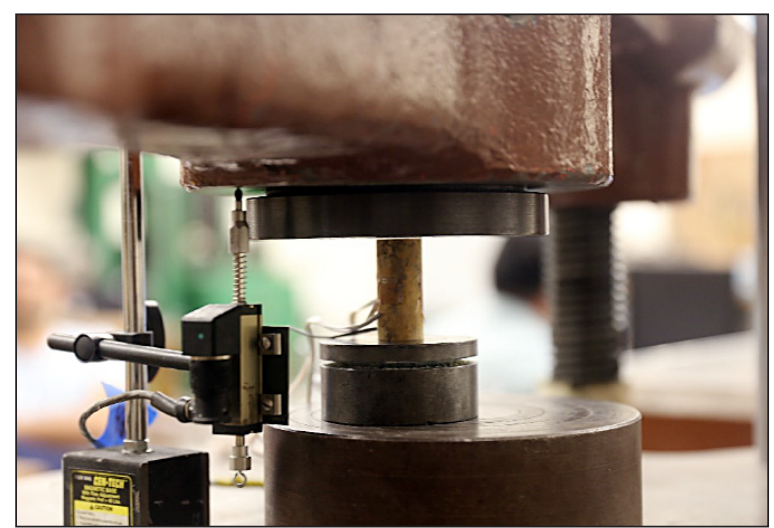

Figure 19. Rock specimen in UTM (spherical swivel at the bottom)

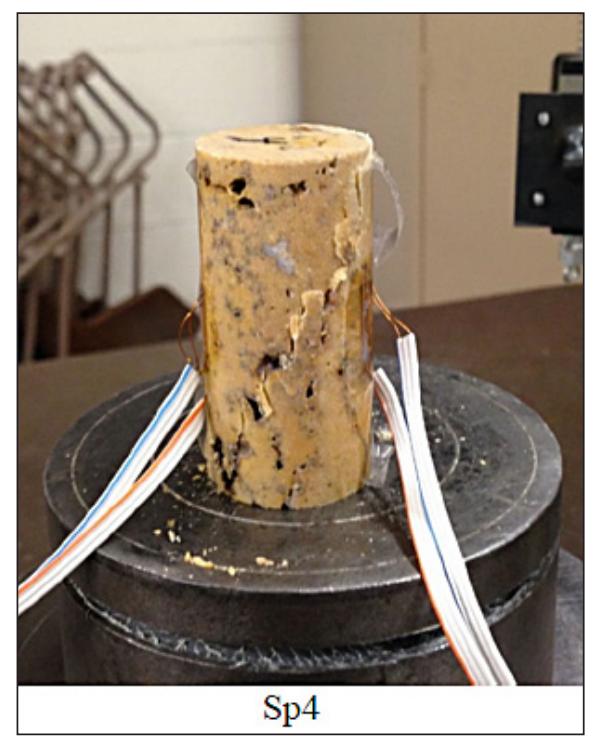

Figure 20. Failure mode of travertine specimen

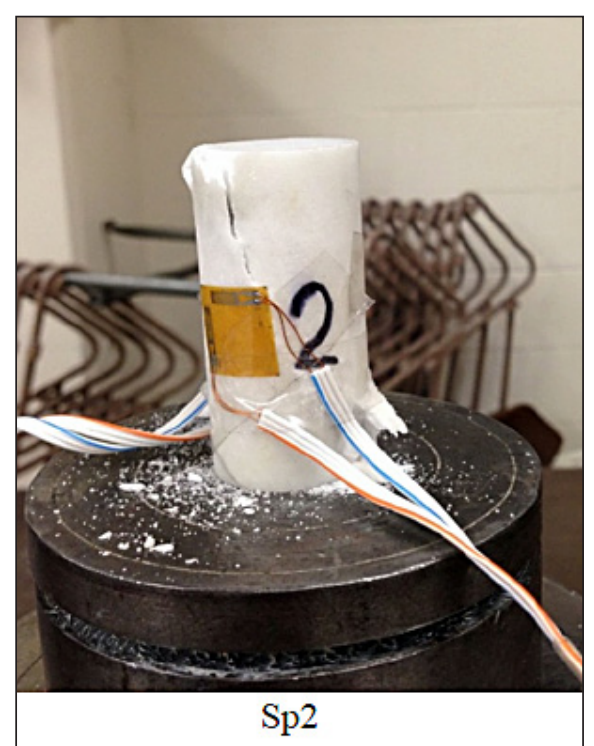

Figure 21. Failure mode of marble specimen

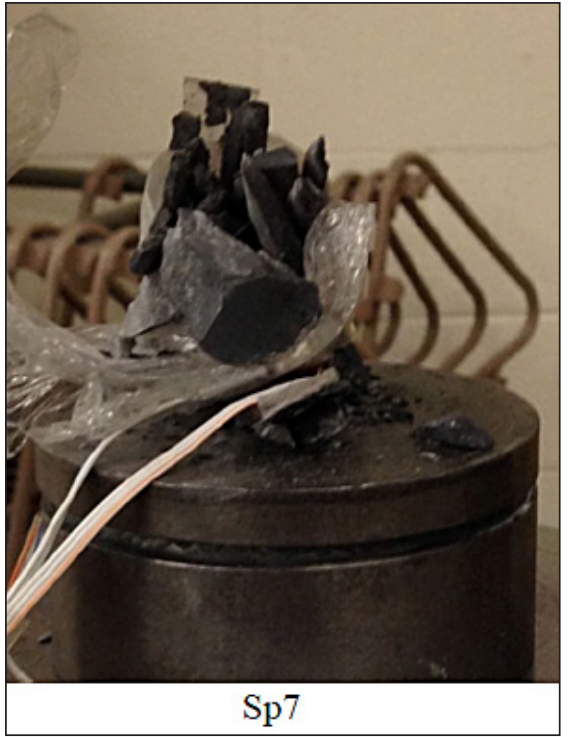

Figure 22. Failure mode of basalt specimen 
Table 6. A summary of test results

\begin{tabular}{|c|c|c|c|c|c|}
\hline Specimen & Color & Load, kips & Pressure, $\mathrm{ksi}$ & Young modulus, $\mathrm{E}$ & Poisson ratio, $\mathrm{v}$ \\
\hline $\mathrm{Sp} 1$ & marble & 6.48 & 8.38 & $5.0 \cdot 10^{3}$ & 0.42 \\
\hline $\mathrm{Sp} 2$ & marble & 7.22 & 9.34 & $4.9 \cdot 10^{3}$ & 0.35 \\
\hline $\mathrm{Sp} 4$ & travertine & 6.74 & 8.72 & $6.9 \cdot 10^{3}$ & 0.28 \\
\hline Sp4.0 & travertine & 8.45 & 10.93 & $9.3 \cdot 10^{3}$ & 0.30 \\
\hline Sp7 & basalt & 35.42 & 45.83 & $10.8 \cdot 10^{3}$ & 0.32 \\
\hline Sp8 & basalt & 34.54 & 44.69 & $10.8 \cdot 10^{3}$ & 0.32 \\
\hline
\end{tabular}

Table 7. Material properties average values used in this research

\begin{tabular}{|l|c|c|c|c|c|c|}
\hline \multirow{2}{*}{} & \multicolumn{3}{|c|}{ Young modulus (GPa) } & \multicolumn{3}{|c|}{ Poisson ratio } \\
\cline { 2 - 7 } & Sp1 & Sp2 & Avg & Sp1 & Sp2 & Avg \\
\hline Marble & 34.4 & 26.7 & 30.5 & 0.42 & 0.35 & 0.39 \\
\hline Travertine & 47.7 & 64.3 & 56.0 & 0.28 & 0.30 & 0.29 \\
\hline Basalt & 74.7 & 74.2 & 74.4 & 0.32 & 0.32 & 0.32 \\
\hline
\end{tabular}

surface. The Vickers hardness indenter is made of diamond with a specific geometry. The indenter is pressed into the test specimen surface by a very accurate applied force using a test instrument particularly designed for this purpose. While Vickers hardness testing is applied to both micro and macro-test force range, in this research the macro force range is considered as specified by ASTM standard (E384).

$$
\text { Macro }>9.81 \text { to } \leq 1176.80 \mathrm{~N}(>1 \text { to } \leq 120 \mathrm{kgf})
$$

As the diamond is pressed into the test specimen, a light microscope measures the indentation size. The macro-range indents are measured in $\mathrm{mm}$ and Vickers hardness is reported in GPa and based on geometry it is calculated as:

$$
H_{v}=0.0018544 \times\left(\frac{P_{2}}{d_{2}^{2}}\right)
$$

where: $P_{2}-$ force, $\mathrm{N}$,

$d_{2}-$ mean diagonal length of the indentations, $\mathrm{mm}$.

An ideal Vickers indenter is a highly polished, pointed, and square-based pyramid shape diamond with face angle of $136^{\circ}$. The four faces of the indenter are equally inclined to the axis of the indenter where they meet at a sharp point.

The test machine used for the tests is designed to support the specimen tested and apply the controlled preselected force while measuring the movement of the indenter. Equipped with a light optical microscope, the tester is capable of selecting a desired test location to measure the size of the indentation produced by the test. The hard- ness testing machine has two indenters and several optical microscopes for getting a good look at the indentation. The specimen surface plane should be perpendicular to the axis of the indenter and the direction of the applied force. It is worth noting that during the entire test cycle, the test machine should be shielded from any form of vibration to ensure accurate results.

Although there is no standard shape or size to the Vickers hardness test specimen, it must conform to a few rules established by ASTM (E384). To achieve optimum accuracy of measurement, the test should be performed on a flat specimen with a polished (or suitably prepared) surface. The required surface finish quality can vary with applied forces and magnifications used where the lower the test force and smaller the indentation size the more critical is the surface preparation.

The Vickers hardness tests were conducted at two different external labs, IdiNet and Struers. The results shown in Table 8 represent the averages of the tests performed by each lab. The data for these tests is shown in Figures 23-25.

Table 8. IDI and Struers Vickers hardness test results

\begin{tabular}{|l|c|c|c|}
\hline & $\begin{array}{c}\text { IdiNet avg } \\
(\mathrm{GPa})\end{array}$ & $\begin{array}{c}\text { Struers avg } \\
(\mathrm{GPa})\end{array}$ & Average \\
\hline Basalt & $1.50 \pm 0.12$ & $1.58 \pm 0.04$ & $1.54 \pm 0.8$ \\
\hline Marble & $1.49 \pm 0.14$ & $1.45 \pm 0.08$ & $1.47 \pm 0.11$ \\
\hline Travertine & $1.27 \pm 0.11$ & $1.41 \pm 0.18$ & $1.33 \pm 0.14$ \\
\hline
\end{tabular}

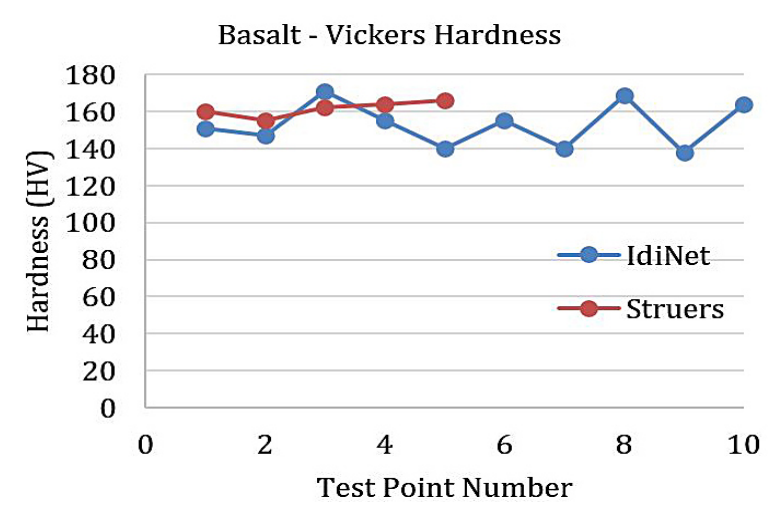

Figure 23. Basalt Vickers hardness test results 


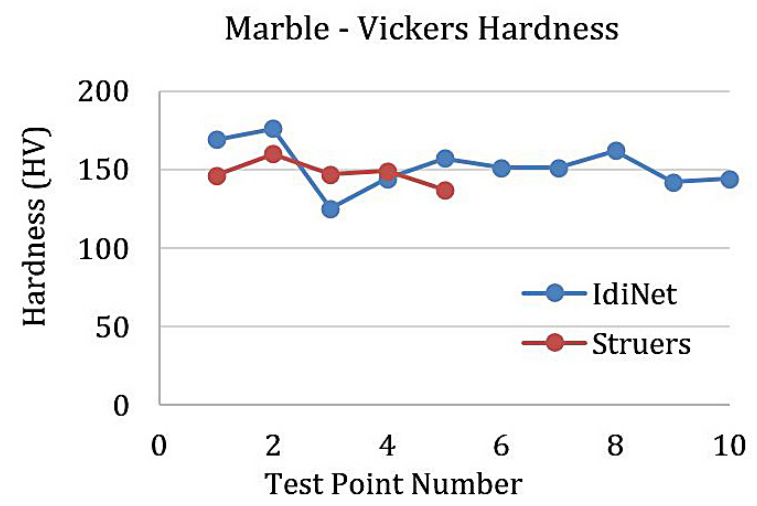

Figure 24. Marble Vickers hardness test results

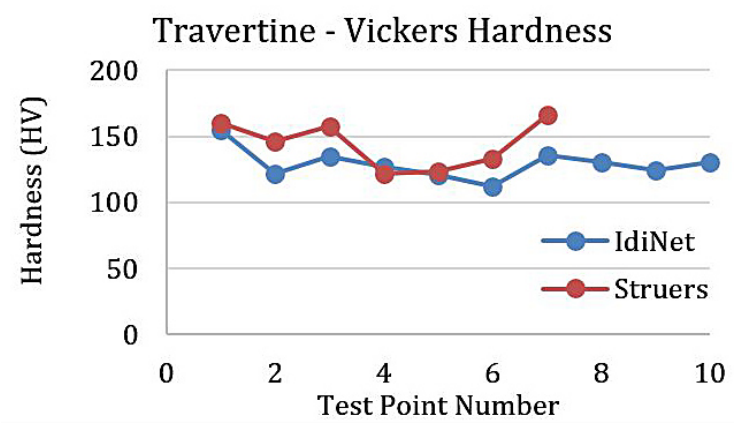

Figure 25. Travertine Vickers hardness test results

\section{Fracture toughness test}

The most suitable fracture toughness test for rock is reported to be the Cracked Chevron Notched Brazilian Disc (CCNBD) test as discussed by Zhao [15]. Fracture toughness is a property that characterizes intact materials resistance to crack propagation. This test is also useful as an index for rock fragmentation processes, like crushing and tunnel boring, or used in the analysis of hydraulic or explosive fracturing and stability.

The test used in this study was applied on core specimens of rock materials where the core axis can be oriented either parallel or perpendicular to any anisotropy features such as planes of weakness. A cracked chevron notched Brazilian disc (CCNBD) specimen has a notch with a chevron "V"-shaped notch cut along the core diameter (Figure 26). One of the advantages of this test is that it only requires the recording of the maximum load in order to calculate the rock fracture toughness in mode I.

The test requires that all the dimensions of the geometry should be converted into dimensionless parameters with respect to the specimen radius $R$ or diameter $D$. The following table contains the definition and values of the geometrical parameters (Table 9) followed by the dimensionless expressions:

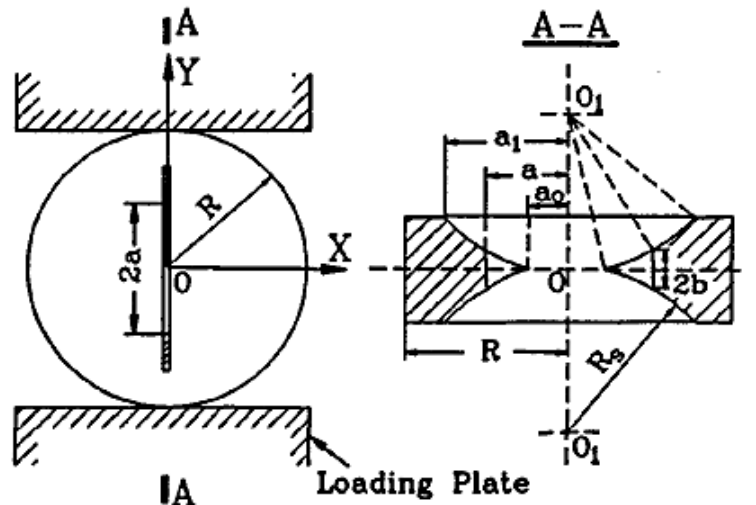

Figure 26. The CCNBD specimen geometry with recommended test fixture, Zhao [16]

Table 9. Standard CCNBD and geometrical dimensions

\begin{tabular}{|l|c|}
\hline \multicolumn{1}{|c|}{ Descriptions } & Values \\
\hline Diameter $\mathrm{D}(\mathrm{mm})$ & 75.00 \\
\hline Thickness B $(\mathrm{mm})$ & 30.00 \\
\hline Initial chevron notched crack length $\mathrm{a}_{0}(\mathrm{~mm})$ & 9.89 \\
\hline Final chevron notched crack length $\mathrm{a}_{1}(\mathrm{~mm})$ & 24.37 \\
\hline Saw diameter $\mathrm{D}_{\mathrm{s}}(\mathrm{mm})$ & 52.00 \\
\hline Cutting depth $\mathrm{h}_{\mathrm{c}}(\mathrm{mm})$ & 16.95 \\
\hline $\mathrm{Y}^{*}{ }_{\min }(-)$ & 0.84 \\
\hline $\mathrm{a}_{\mathrm{m}}(\mathrm{mm})$ & 19.31 \\
\hline
\end{tabular}

$$
\begin{aligned}
& \alpha_{o}=a_{o} / R=0.2637 \\
& \alpha_{1}=a_{1} / R=0.65 \\
& \alpha_{B}=B / R=0.8 \\
& \alpha_{m}=a_{m} /_{R}=0.5149 \\
& \alpha_{s}=D_{s} /_{D}=0.6933
\end{aligned}
$$

The following equation is used to calculate specimen fracture toughness:

$$
K_{I C}=\frac{P_{\max }}{B \cdot \sqrt{D}} \cdot Y_{\min }^{*}
$$

Where $Y_{\min }^{*}$ is the critical dimensionless stress intensity value for the specimen that is determined by the specimen geometry dimensions $\alpha_{\mathrm{o}}, \alpha_{1}$, and $\alpha_{\mathrm{B}}$ only.

$$
Y_{\min }^{*}=u \cdot e^{v \cdot \alpha_{1}}
$$

Where $u$ and $v$ are constant determined by $\alpha_{o}$, and $\alpha_{\mathrm{B}}$ only. The tabulated values of $u$ and $v$ are listed in Zhao [15].

Tests were conducted on one specimen each for marble and travertine rock specimens. Basalt rock could not be tested due to the limitation of the 
saw available to cut through the specimen that is thicker than the other two specimens. Therefore, $\mathrm{K}_{\mathrm{IC}}$ plot was generated for the basalt rock material where the fracture toughness reasonable range values were used yielding the WOB required for each $\mathrm{K}_{\mathrm{IC}}$ value. The WOB value that matched or very close to the WOB from the experiment was chosen to be the $\mathrm{K}_{\mathrm{IC}}$ value for basalt:

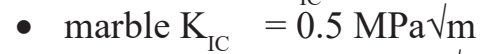

- travertine $\mathrm{K}_{\mathrm{IC}}=0.7 \mathrm{MPa} \sqrt{\mathrm{m}}$

- basalt $\mathrm{K}_{\mathrm{IC}} \quad=1.2 \mathrm{MPa} \sqrt{\mathrm{m}}$

Travertine, marble, and basalt rocks material properties are tested and collected as shown in Table 10.

\section{EXPERIMENTAL SETUP}

Rotary ultrasonic drilling experiments were performed using the Sonic Mill Rotary Ultrasonic Machine, Series 10 (Sonic-Mill, Albuquerque, NM, USA), located in the Industrial Engineering Laboratory at the Kansas State University [http://catalog.k-state.edu/content. php? navoid $=144 \&$ catoid $=2] . \quad$ The experiment setup consists of three major systems: an ultrasonic spindle system, a coolant system, and a data acquisition system.

\section{Ultrasonic spindle system}

The ultrasonic spindle system consists of the following components as shown in Figure 27.

Motor speed controller - supplies the rotation motion of the core drill and the motor speed controller could be used to obtain different speeds.

Power supply - that converts $60 \mathrm{~Hz}$ electrical power supply to high frequency of $20 \mathrm{kHz} \mathrm{AC}$ output. This AC output is fed to the piezoelectric transducer located in the ultrasonic spindle.

Ultrasonic spindle - contains piezoelectric transducer: converts the electrical AC input received from the power supply into mechanical vibration.

The data acquisition system - centers around measuring the force applied to the workpiece, or the WOB. The system consists of a piezoelectric dynamometer (Kistler 9272) is attached to the machine table and the workpiece is mounted on top of it with fixtures. The dynamometer measures the cutting force along the feed direction (WOB) generating an electrical. A/D converter: receives the electrical signal from the dynamometer and displays it and saves it to a computer system with the help of Dynoware software. The coolant system is activated at the beginning of each drilling test and coolant is continuously supplied to the drill bit to prevent overheating.

When performing the measurements to determine the WOB under the various testing conditions, the workpiece is placed and fastened atop Kistler 9272 piezoelectric dynamometer attached to the machine table. Cutting force sampling frequency signal is set at $1000 \mathrm{~Hz}$.

\section{Ultrasonic wave amplitude}

It is evaluated based on the drill power using a dial gage (Figure 28a). Also, drill bit tuning length is taken in account in assessing the amplitude as shown in the image below considering the optimum value is at the multiple of an integer by half the ultrasonic wavelength (Figure 28b). All drill bits used are in the length and amplitude val-

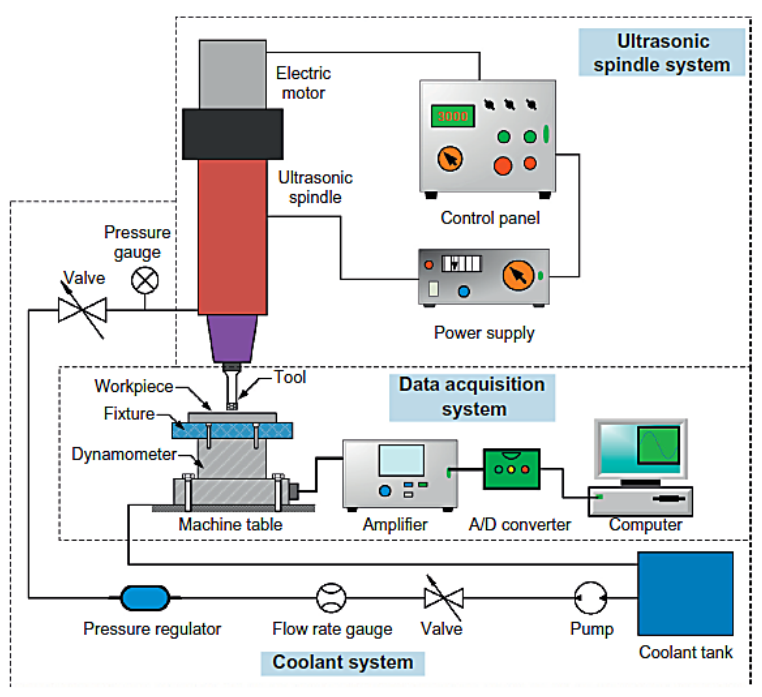

Figure 27. Schematic of Rotary Ultrasonic Machine (RUM) at KSU, Cong [7]

Table 10. Rocks materials properties tests summary

\begin{tabular}{|l|c|c|c|c|}
\hline \multicolumn{1}{|c|}{ Rock type } & $\begin{array}{c}\text { Elastic modulus } \mathrm{E} \\
(\mathrm{MPa})\end{array}$ & $\begin{array}{c}\text { Fracture toughness } \mathrm{K}_{\mathrm{c}} \\
{[\mathrm{MPa} \sqrt{\mathrm{m}}]}\end{array}$ & $\begin{array}{c}\text { Vickers hardness } \mathrm{H}_{\mathrm{v}} \\
(\mathrm{GPa})\end{array}$ & Poisson's ratio $\mathrm{v}$ \\
\hline Basalt (igneous) & 74.4 & 1.2 (estimated) & 1.54 & 0.32 \\
\hline Marble (metamorphic) & 31.5 & 0.5 & 1.47 & 0.39 \\
\hline Travertine (sedimentary) & 56.0 & 0.7 & 1.34 & 0.29 \\
\hline
\end{tabular}


ues of drill bit \# showing in the literature below as discussed by Cong [5] (Figure 30 and 31). Testing was performed according to the matrix specified in Table 2. All core rock samples were collected for each test, grouped and labeled with the test parameters values (Figure 32).

\section{Drill bits}

Ten core drills, three of which have same specification, with metal-bond diamond abrasive particles were provided by N.B.R. Diamond Tool Corp. (La Grangeville, NY, USA). The drill bit specifications are listed in Table 11. The diamond particles were provided by National Research Co. Nat-PGE. The bond between the abrasive particles and the matrix is bronze, Colmonoy \#7 with a Rockwell hardness of B 92-97. The body of the drill is cold rolled seamless tubing made of 1215 steel.
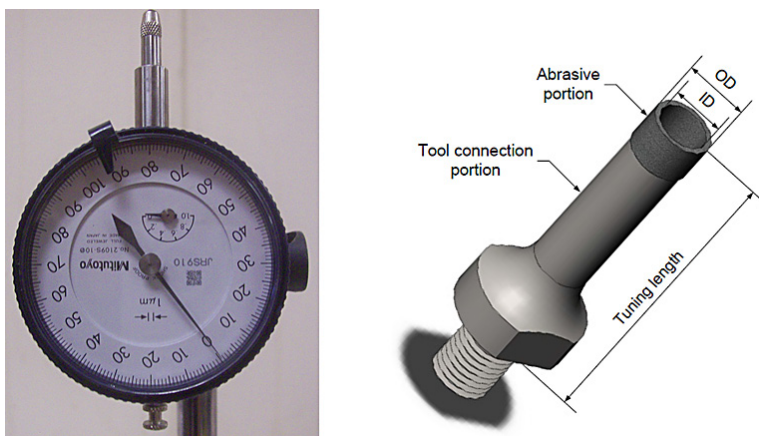

Figure 28. a) Amplitude measuring device, dial gage, b) Typical drill bit showing tuning length, Cong [6]

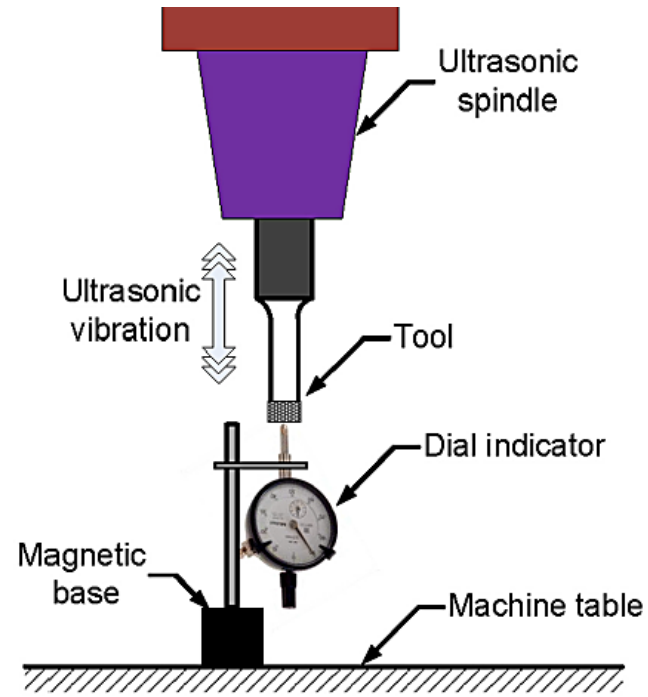

Figure 29. Dial gage placed under the drill bit and in contact with the surface as it operates and measure the wave amplitude
To ensure identical comparison of drill bit performance condition, the drill bit tip (cutting surface) is refreshed between each test using sharpening / dressing stick. The dressing process involves removing the worn out abrasive diamond particles and exposing a new surface containing new sharp diamond particles.

\section{Core drill bit design parameters}

As the core drill bit diameters changes, the end face area changes are resulting in an increase or decrease in the number of the abrasive particles taking part in cutting. Therefore, the changes of

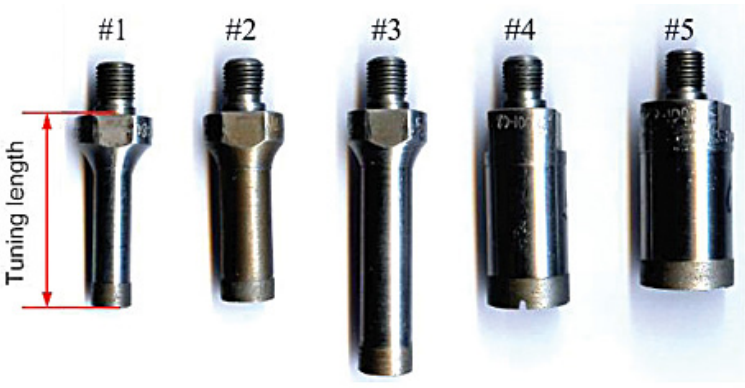

Figure 30. Five different tools used in the study, Cong [5]

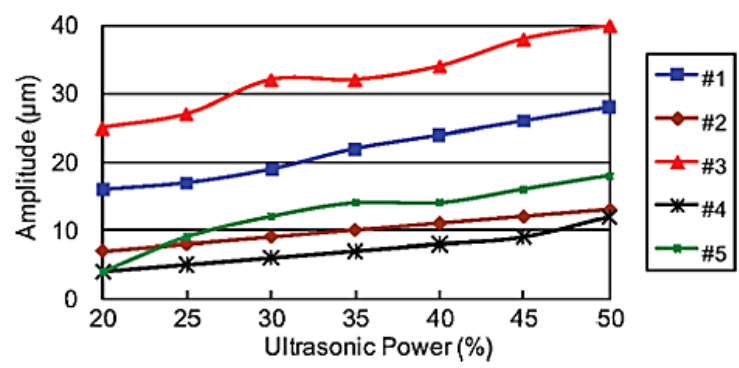

Figure 31. Effects of ultrasonic power on vibration amplitude (measure with the dial indicator method) for five tools (\#1, \#2, \#3, \#4, and \#5), Cong [5]

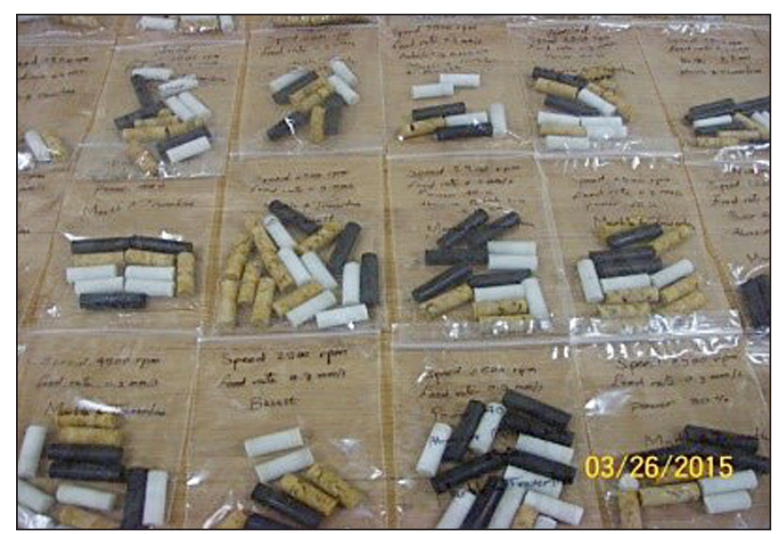

Figure 32. Rock samples drilled at various input parameters close up view showing the labeling system applied to identify each core sample 
Table 11. Drill bits specifications

\begin{tabular}{|c|c|c|c|c|}
\hline $\begin{array}{c}\text { Abrasive size } S_{a} \\
(\mathrm{~mm})\end{array}$ & Abrasive concentration $C_{a}$ & $\begin{array}{c}\text { Drill bit outer diameter } D_{o} \\
(\mathrm{~mm})\end{array}$ & $\begin{array}{c}\text { Drill bit inner diameter } D_{i} \\
(\mathrm{~mm})\end{array}$ & Mesh size \\
\hline 0.125 & 50 & 12 & 10 & $\# 100-120$ \\
\hline 0.125 & 100 & 12 & 10 & $\# 100-120[3]$ \\
\hline 0.125 & 150 & 12 & 10 & $\# 100-120$ \\
\hline 0.080 & 100 & 12 & 10 & $\# 140-170$ \\
\hline 0.160 & 100 & 12 & 10 & $\# 80-100$ \\
\hline 0.200 & 100 & 12 & 10 & $\# 60-80$ \\
\hline 0.125 & 100 & 9 & 7 & $\# 100-120$ \\
\hline 0.125 & 100 & 15 & 13 & $\# 100-120$ \\
\hline
\end{tabular}

the drill bit inner and outer diameters will be related to the performance of the drill.

Three different drill bit sizes were selected to investigate the effect of the change of the bit inner and outer diameter on ROP performance. While the model shows the change of ROP as the drill bit size changes at a constant force, the experiments obtain the force required to cut through the rock sample as an output at a constant feed-rate/ROP as an input. Therefore, to validate the mathematical model, the range of average drill bit size shown in Table 2 was tested at as the rest of the listed parameter set at their listed nominal values. The results of cutting force with error bars (WOB) vs drill bit average diameter is shown in Figure 33.

Three different abrasive particles concentrations $\left(C_{a}\right)$ in the drill bit are shown in Table 2 were tested as the rest of the listed parameters were set at their listed nominal values. The results of cutting force (WOB) vs abrasive particle concentration is shown in Figure 34.

Four different abrasive particles sizes $\left(S_{a}\right)$ in the drill bit are shown in Table 2 were tested as the rest of the listed parameters were set at their listed nominal values. The results of cutting force (WOB) vs abrasive particle size is shown in (Figure 35).

\section{Drill process parameters}

Nominal drill bit size was chosen with inner diameter $D_{i}=10 \mathrm{~mm}$ and outer diameter $D_{o}=12$ $\mathrm{mm}$ to use in conducting weight on bit at rates of penetration between $0.1-0.7 \mathrm{~mm} / \mathrm{s}$ as shown in Table 2. The rest of the listed parameters were set at their listed nominal values. The results of cutting force with error bars (WOB) vs ROP are shown in Figure 36. Four different spindle speeds $(S)$ as shown in Table 2, were tested as the rest of the listed parameters were set at their nominal values. The results of cutting force with error bars (WOB) vs spindle speed is shown in Figure 37.

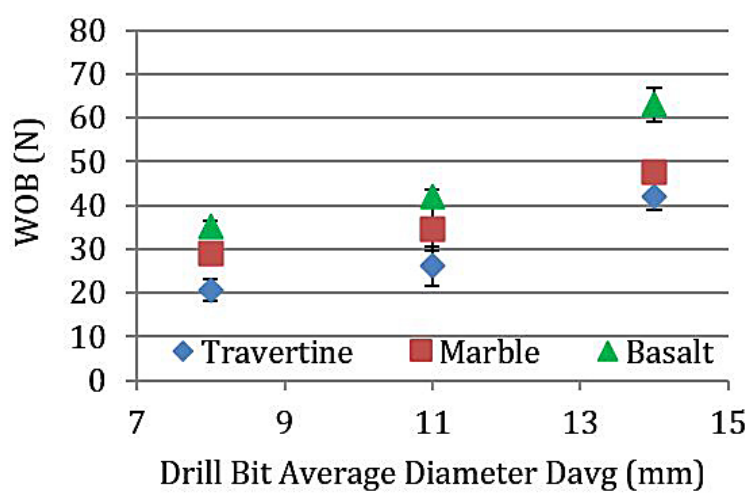

Figure 33. Experimental results of the cutting force vs dill bit average diameter

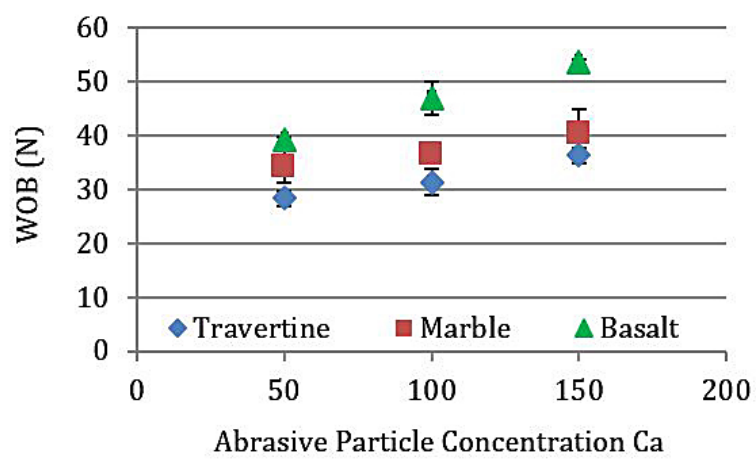

Figure 34. Experimental results of the cutting force vs cross abrasive particles concentration

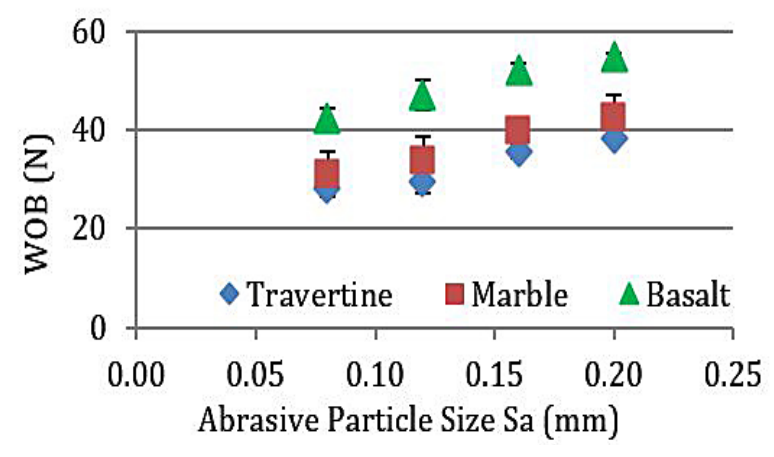

Figure 35. Experimental results of the cutting force vs cross abrasive particles size 


\section{Ultrasonic wave parameters}

Four different ultrasonic amplitudes $(A)$ are shown in Table 2 were tested as the rest of the listed parameters were set at their listed nominal values. The results of cutting force (WOB) vs ultrasonic amplitude is shown in (Figure 38). The change in frequency $(f)$ is not investigated in this research.

\section{MATHEMATICAL MODEL VALIDATION}

Comparison of the input variables effect on the on WOB performance has been examined analytically and experimentally. Performance evaluations were conducted at nominal values for

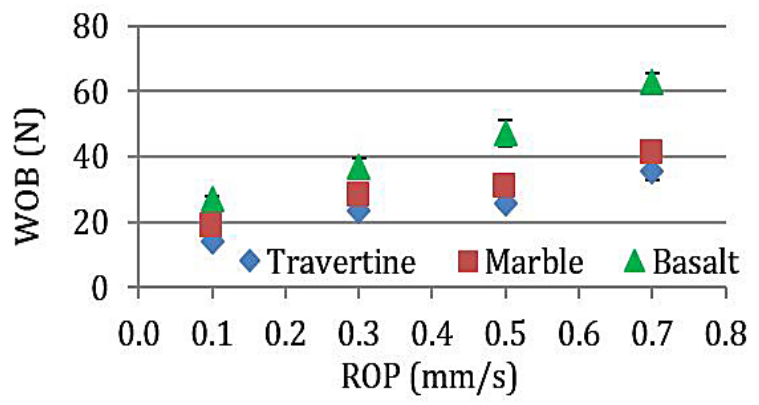

Figure 36. Experimental results of the cutting force vs ROP

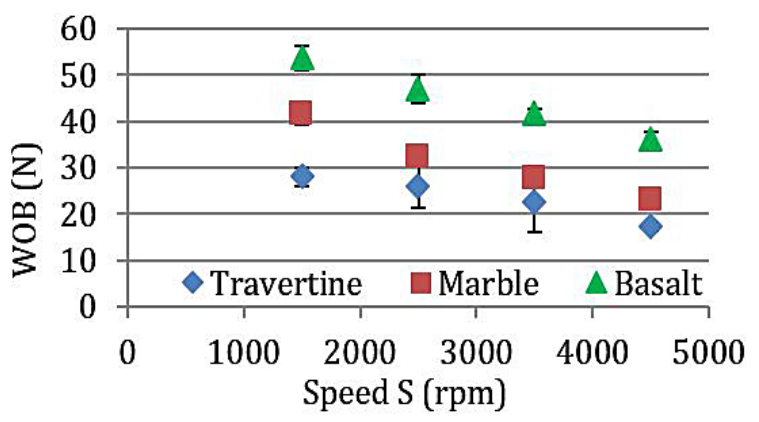

Figure 37. Experimental results of the cutting force vs Speed

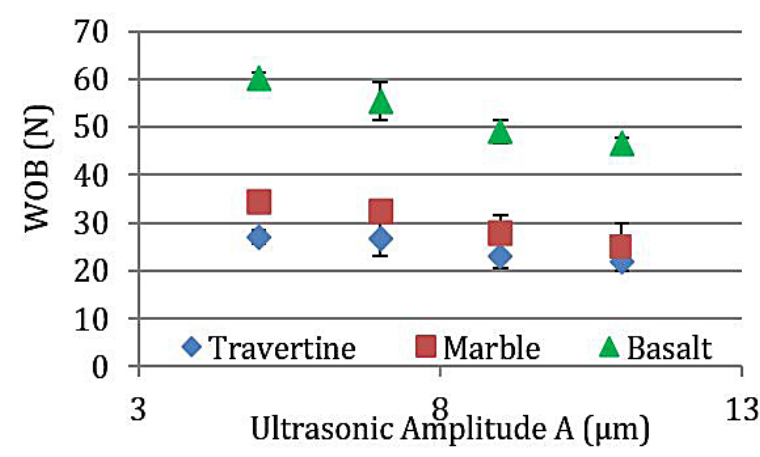

Figure 38. Experimental results of the cutting force vs ultrasonic amplitude all parameter with the variation of one parameter at a time within acceptable range values as follow: speed $S=2500 \mathrm{rpm}$, abrasive particle size $S_{a}$ $=0.125 \mathrm{~mm}$, abrasive particle concentration $C_{a}=$ 100 , drill bit outside diameter $D_{o}=12 \mathrm{~mm}$, drill bit inside parameter $D_{i}=10 \mathrm{~mm}$, abrasive particle semi-angle $\alpha_{\mathrm{o}}=120^{\circ}$, ultrasonic wave amplitude $A=7 \mu \mathrm{m}$, and ROP $=0.3 \mathrm{~mm} / \mathrm{s}$. Furthermore, materials properties were obtained from tests conducted determining elastic modulus $E$, Poisson's ratio $v$, fracture toughness $K_{I C}$, and Vickers hardness $H_{v}$ for each type of rock (basalt, marble and travertine).

Although, the mathematical model is developed for ROP, the experiments were conducted on a rotary ultrasonic drill machine that allows for holding the feed rate (ROP) constant while measuring the applied force (WOB). Therefore, the predicted results of ROP will not be compared to the experimental results. Instead, the force (WOB) will be calculated using the developed ROP mathematical model and compared to the applied force (WOB) measured in the experiments as each parameter vary within a reasonable range. Alternatively, the applied force (WOB) expression presented below could be used directly.

$W O B=\left[\left(\frac{C_{a}^{1 / 12}(t)^{9 / 8}\left(D_{a v g}\right)^{1 / 8}\left(\tan \frac{\alpha_{o}}{2}\right)^{3 / 4}}{G_{1} S_{a}^{1 / 4}}\right)\right]^{8 / 9} \mathrm{X}$
$\left(\frac{(R O P)\left[\frac{\pi}{2}-\arcsin \left(1-\frac{\delta}{A}\right)\right]^{1 / 8}}{S}\right)\left(\frac{H_{v}^{3 / 2} K_{I C}^{1 / 2}\left(1-v^{2}\right)^{1 / 4}}{E^{7 / 8}}\right)$

where: $G_{1}=\frac{K C_{2}{ }^{2}}{180 C_{1}{ }^{1 / 8}}$

\section{Volume proportionality parameter $K$}

$K$ value was assumed in previous work to be independent of input variables and to be constant for a given workpiece. For a workpiece of alumina for $K$ was found to be, $K=0.295$ as discussed by Liu [11]. The mathematical model developed in Chapter 6 of this discussion also assumed a constant value for $K$ for each type of rock. $K$ was found to be independent of all input variables as shown in the tests' results of all experiments conducted since it vary slightly around an average value.

The value of $K$ remained approximately unchanged, with average value of $K=1.2,0.92$, and 0.64 for marble, travertine and basalt respectively. Average $K$ values over tested parameters with error margins are shown in Figure 39, Figure 40, and Figure 41. As discussed in Chapter 6, $K$ was 


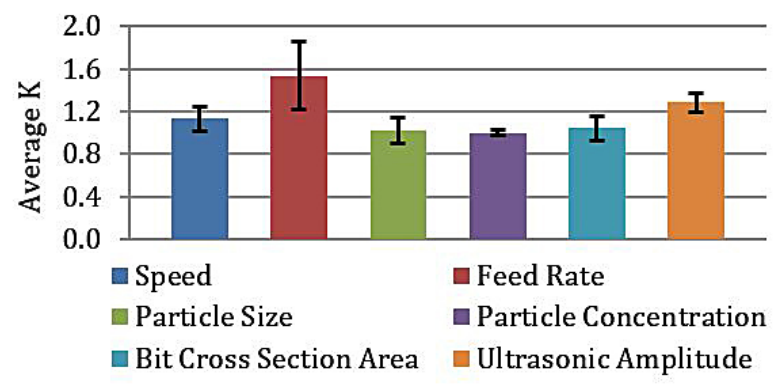

Figure 39. Average $K$ for marble

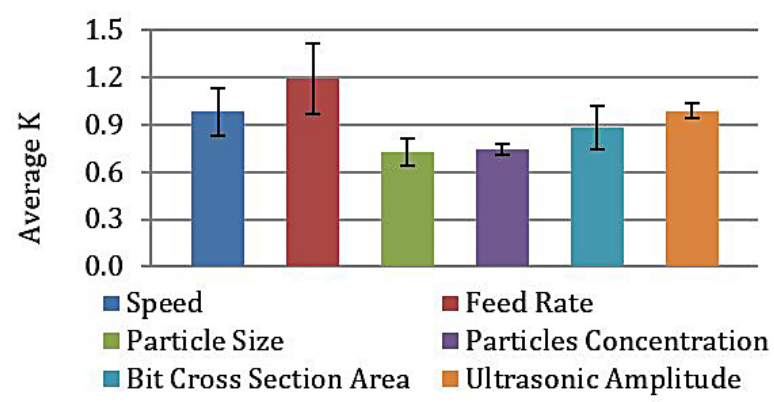

Figure 40. Average $K$ for travertine

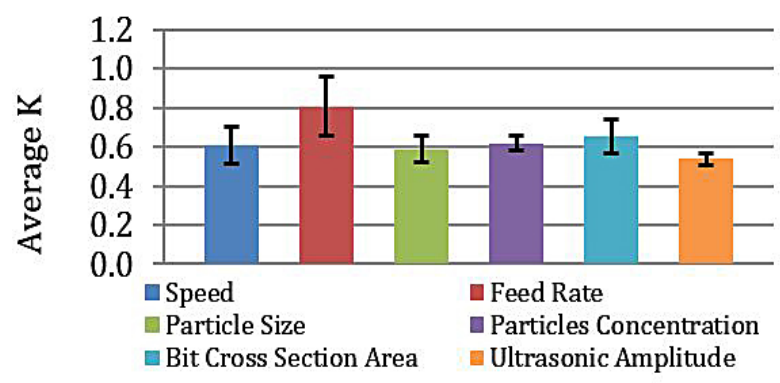

Figure 41. Average $K$ for basalt

obtained as the volume proportionality between theoretical and actual volume: $V=K \cdot V_{o}$.

As shown above that $K$ varied slightly for each workpiece, namely marble, travertine and basalt, using all data generated from experiments. The reason behind the variation is the highly probable overlapped damaged zone generated from each abrasive particle and its neighboring particles. In support of this claim the distance between abrasive particles is evaluated based on the abrasive particle size $S_{a}$, abrasive particles concentration $C_{a}$, and the number of particles $N_{a}$ within the cross section area of the cutting surface $A o$ as follow:

Let the distance between two particles be $d p$

$$
\begin{gathered}
N_{a}=C_{1}\left(\frac{C_{a}^{2 / 3} A_{o}}{S_{a}^{2}}\right) ; \frac{A_{o}}{N_{a}}=\left(\frac{S_{a}^{2}}{C_{1} C_{a}^{2 / 3}}\right) \\
d_{p}=\sqrt{\frac{A_{o}}{N_{a}}}=\sqrt{\frac{S_{a}^{2}}{C_{1} C_{a}^{2 / 3}}}=\frac{1}{\sqrt{C_{1}}}\left(\frac{S_{a}}{C_{a}^{1 / 3}}\right)
\end{gathered}
$$

The distance between two particles from center to center, $d p$, is compared to the two halves of the two particles that adds up to one particle size Sa. The distance between two particles is slightly larger than the size of one particle which is a very good indication that the volume removed could possibly overlap at times. The $x$-axis in the three plots is set for the variation of $S_{a}, C_{a}$, and $A_{o}$. The overlap is expressed in terms of the volume proportionality $K$ explained in details previously.

\section{Core drill bit parameters change effect on WOB}

The mathematical model developed for ROP is applied in determining the effect of the change in the drill bit outer and inner diameter $\left(D_{o}\right.$ and $D_{i}$ ) on the WOB performance. As the drill bit diameters varied, the thickness remained constant at $t=1.0 \mathrm{~mm}$ and nominal values applied to the rest of the parameters as mentioned previously predicting the effect results. The predicted results show that the change in the drill bit outer and inner diameters has little effect on the ROP performance. The analytical model plot below shows the slight increase in the WOB as the drill bit diameter increases for the three different types of rocks (Figure 42). Three average diameters were used: $8 \mathrm{~mm}, 11 \mathrm{~mm}$ and $14 \mathrm{~mm}$. The predicted WOB curves are plotted in Figure 42. As shown in the mathematical model that it predicts WOB to be proportional to $\left(D_{a v g}\right)^{19}$ where little change in WOB is predicted.

The experimental results show an increase in the force when the average diameter increases for the three types of rocks (Figure 43).

The model captures the general trend of increasing WOB with increasing average diameter, but predicts a smaller change than is found in the data. The mathematical model developed for ROP

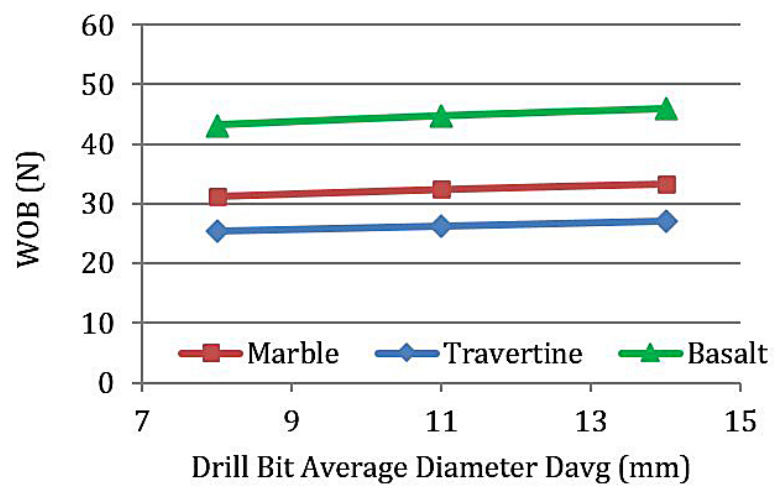

Figure 42. Predicted effect of drill bit diameters on WOB 


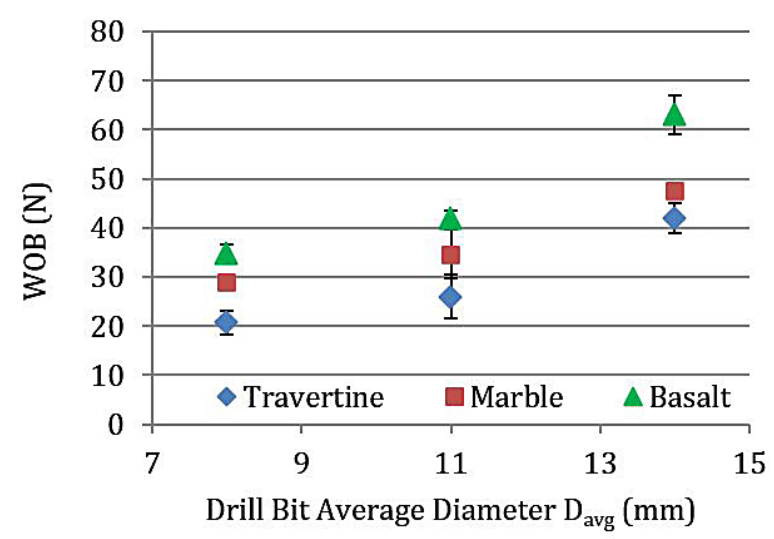

Figure 43. Experimental results of drill bit diameters on cutting force/WOB

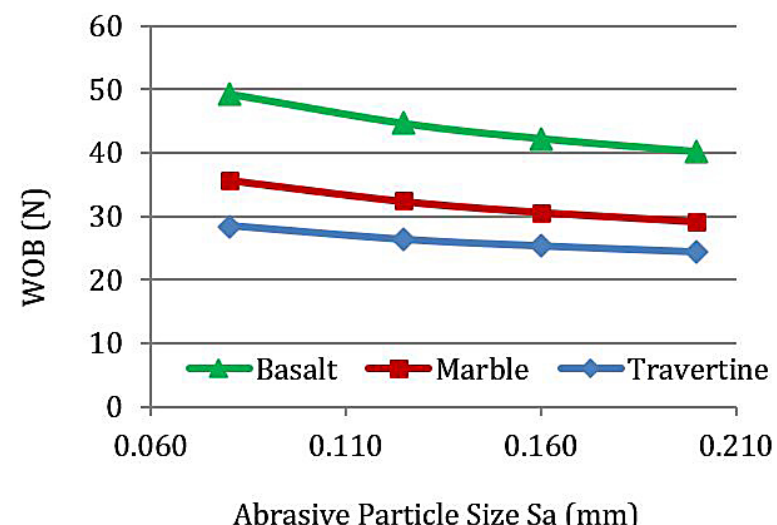

Figure 44. Predicted effect of abrasive particle size on WOB

is applied in determining the effect of the change in the abrasive particle size $S_{a}$ on the ROP performance. As the abrasive particle size varied between $80-200 \mu \mathrm{m}$, the nominal values applied to the rest of the parameters as mentioned previously predicting the effect results. Predicted results shows that the increase in the abrasive particle size causes the WOB to decrease. The model predicts WOB is proportional to $S_{a}^{-2 / 9}$, see Figure 44.

The experimental results show an increase in the WOB as the abrasive particle size $S_{a}$ for the three types of rocks (Figure 45). This result is different from the developed model that shows decrease in WOB as $S_{a}$ increases. Therefore, the change in the abrasive particle size parameter's effect on the ROP performance is not well presented by the developed model. The model does not capture the observed effect for this parameter.

The mathematical model developed for ROP is applied in determining the effect of the change in the abrasive particle concentration $C_{a}$ on the WOB applied. As the abrasive particle concentration varied between 50 and 150 , the nominal val-

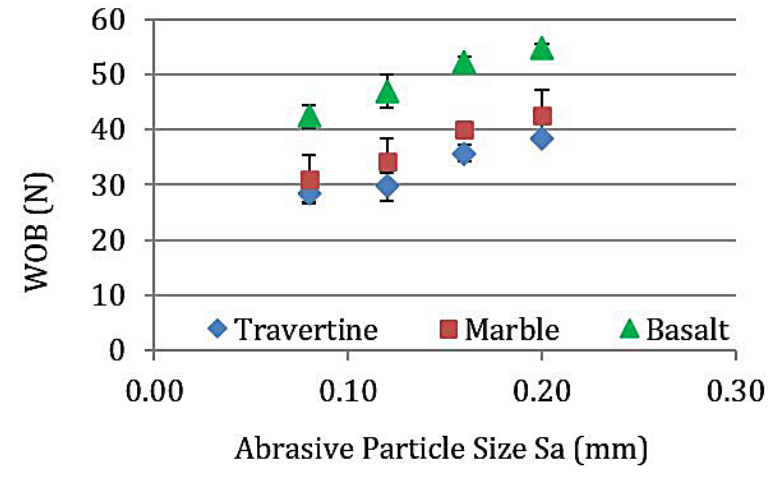

Figure 45. Experimental results of the abrasive particle size effect on cutting force/WOB

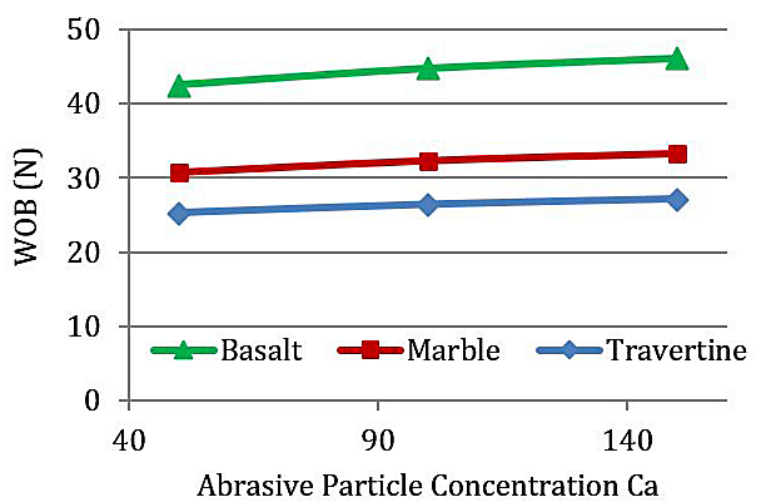

Figure 46. Predicted effect of abrasive particle concentration on WOB

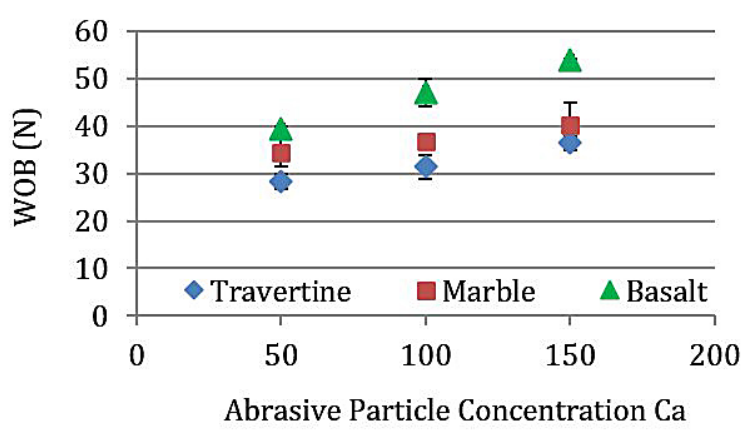

Figure 47. Experimental results of the abrasive particle concentration effect on cutting force/WOB

ues applied to the rest of the parameters as mentioned previously predicting the effect results. The predicted results show that the increase in the abrasive particle concentration has little effect were WOB is proportional to $C_{a}^{227}$, as shown for the three different types of rocks (Figure 46).

The experimental results show a moderate increase in the WOB as a result to the increase in the abrasive particle concentration for the values of 50, 100 and 150 for the three types of rocks (Figure 47). The model shows the same trend as the data in the performance of the abrasive particle concentration. 


\section{Process parameter change effect on WOB}

The effect of the process parameters such as WOB and spindle speed on the ROP performance are investigated where the predicted results are compared to the experimental results with an objective of validating the developed ROP mathematical model.

\section{Rate of penetration (ROP)}

The model predicted result shows that the change in the feed rate ROP results in a significant increase in WOB as it is predicted to be proportional to $R O P^{89}$ as shown in Figure 48. As the applied feed rate increased from 0.1 to $0.7 \mathrm{~mm} / \mathrm{s}$ the WOB increased corresponding to the rock strength. The experimental results show significant increase in the force applied as a result to the increase in the rate of feed rate (ROP) for the same values $(0.1,0.3,0.5$, and $0.7 \mathrm{~mm} / \mathrm{s})$ for the three types of rocks (Figure 49).

As shown above, that the model represents the trend in the ROP performance shown in the experimental data. The difference in the slopes of the experimental results compared with the model could be a result of the rotary ultrasonic drill ma-

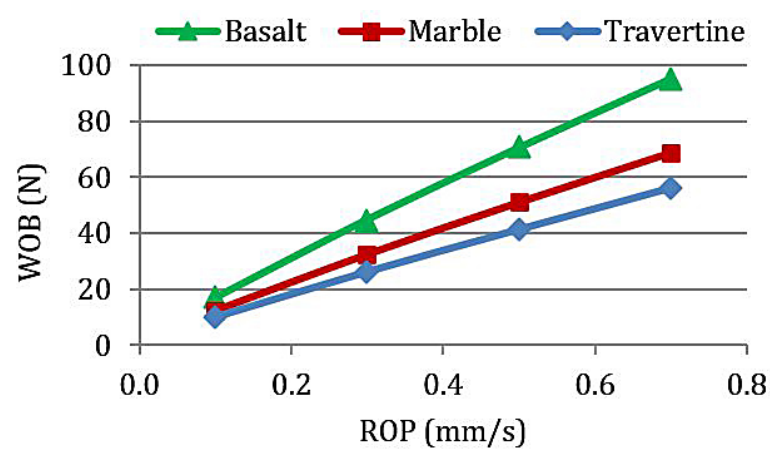

Figure 48. Predicted effect of applied force on ROP performance for basalt rock

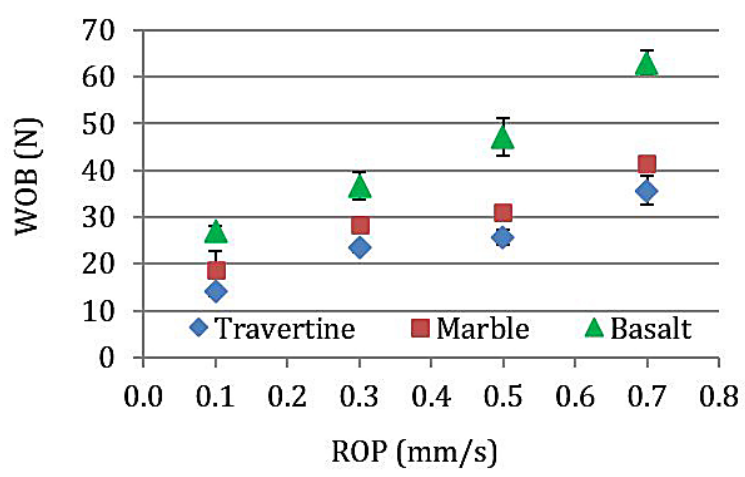

Figure 49. Experimental results of the feed rate/ROP effect on cutting force/WOB chine operation that requires manual setup of the feed rate applied. The manual setup utilizes a dial gauge and a timer to specify the desired feed rate. The human error participate in this process has an effect on the slightly different resulted slopes between the model and the experiments.

\section{Speed (S)}

The mathematical model developed for ROP is applied in determining the effect of the change of the spindle speed on the WOB applied. As the spindle speed varied between 1500 and 4500 $\mathrm{rpm}$, the nominal values applied to the rest of the parameters as mentioned previously predicting the effect results on WOB. The predicted results show that the increase in the spindle speed should cause significant decrease in the WOB (WOB scales as $S^{-9 / 8}$ ) for the three different types of rocks (Figure 50).

The experimental results also show significant decrease in the WOB as a result to the increase in the spindle speed for the three types of rocks (Figure 49). These results show that the model is in general agreement with the experimental results for the spindle speed performance and its effect.

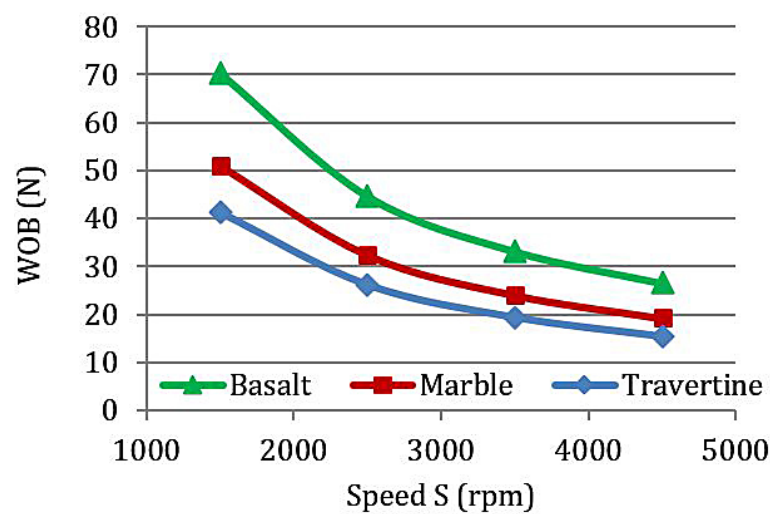

Figure 50. Predicted effect of spindle speed on WOB

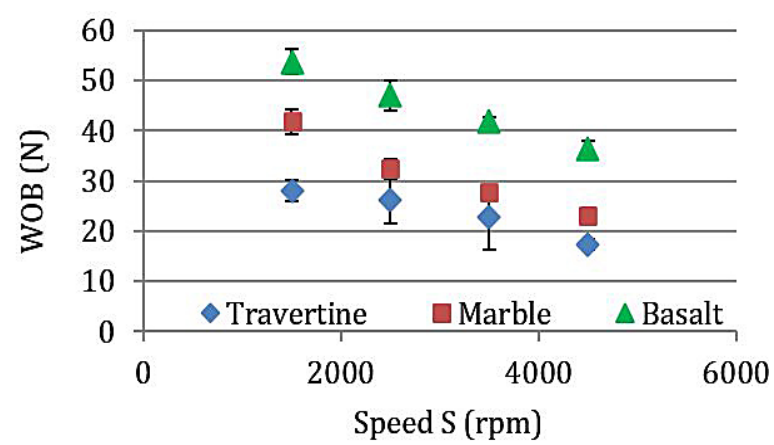

Figure 51. Experimental results of the speed effect on cutting force/WOB 


\section{Ultrasonic amplitude $(A)$}

The effect of the ultrasonic wave parameters such as amplitude and frequency on the WOB performance are investigated where the predicted results are compared to the experimental results with the objective of validating the developed mathematical model. Furthermore, the model suggests no dependence on ultrasonic frequency $f_{u}$ and only amplitude variable is considered in this study. The mathematical model developed for ROP is applied in determining the effect of the change of the ultrasonic wave amplitude on the WOB performance. As the amplitude varied between 5-11 $\mu \mathrm{m}$, the nominal values applied to the rest of the parameters as mentioned previously predicting the effect results. The predicted result shows that the change in the ultrasonic wave amplitude should have little effect on the applied WOB for the three different types of rocks (Figure 52).

The experimental results show a more substantial decrease in the force applied as a result of the increase in the ultrasonic wave amplitude also from 5-11 $\mu \mathrm{m}$ for the three types of rocks (Figure 53). The mathematical model results agree on the

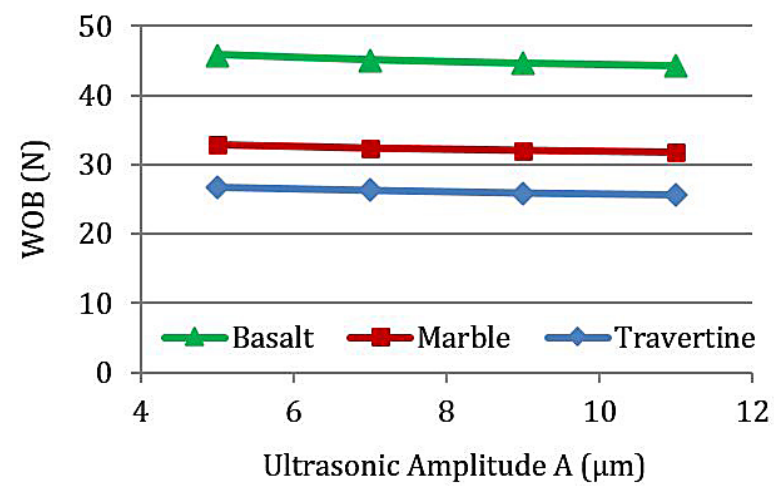

Figure 52. Predicted effect of ultrasonic wave amplitude on ROP performance for basalt rock

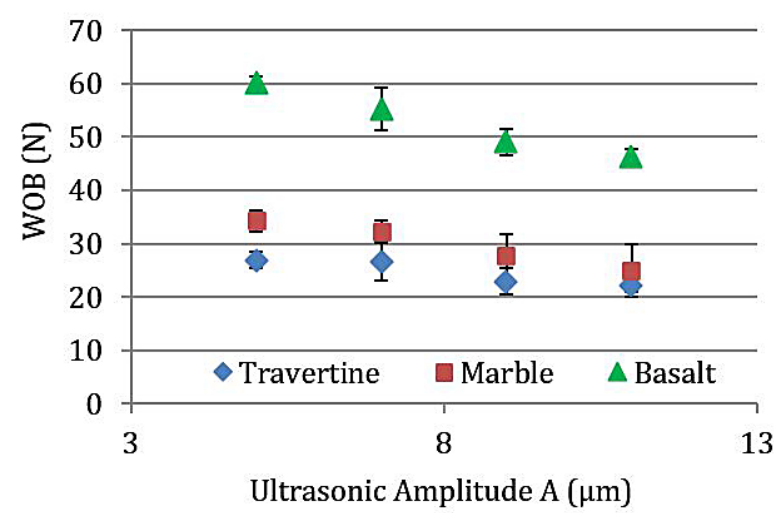

Figure 53. Experimental results of the ultrasonic wave amplitude effect on cutting force/WOB sense of the effect due to an increase in ultrasonic amplitude, but not on the magnitude.

\section{CONCLUSIONS}

Drilling on Mars is a huge engineering challenge. Previous research shows that drilling under simulated Martian conditions is, for many reasons, very different from drilling under terrestrial conditions. As researchers conducted their investigations under Martian conditions, they found that Mars has environmental and technological constraints and examining them led to many discoveries, which otherwise would have remained unnoticed. Future research will be conducted applying the mathematical model developed in this paper drilling in various types of rocks under Mars condition.

This research investigates rotary ultrasonic drilling as an alternative technique drilling in brittle materials. This approach is predicted to have a higher performance compared to currently used percussive drilling techniques. The study presented in this dissertation focused on developing a mathematical model of the rate of penetration (ROP) using rotary ultrasonic drilling, identifying all parameters involved in drilling, and finally predicting the different parameters' effect on drilling performance. Drilling experiments on three different types of rocks that vary in strength from low strength rock such as travertine, a medium strength rock such as marble and very hard rock such as basalt were conducted. Predicted results from the mathematical model were validated by comparing them to the experimental results.

Although there have been models of Rotary Ultrasonic Machining (RUM), they mostly focused on predicting material removal rate (MRR) or investigating material removal mechanism. A few focused on predicting the cutting force model for RUM of ductile materials. At present, no publications are available on rate of penetration model for RUM of brittle materials. Therefore, to optimize the drilling input variables, it was necessary to develop a model for ROP performance for RUM of brittle materials.

The mathematical model showed promising results of predicting the WOB performance as the input parameters change using the same drill bit on the three different types of rocks that varied in strength. 


\section{Drilling parameters and their effect on rate of penetration performance}

The mathematical model for the rate of penetration (ROP) was developed by analyzing a single abrasive particle as the basic component of cutting by a diamond impregnated drill bit. The ROP model was derived by summing up all forces exerted by all diamond particles taking part in cutting, following earlier work involving cutting force models of variety of abrasive particles as discussed by Zhang [14].

It is important to point out the key assumptions made in developing the mathematical model:

1) All workpieces used in this study are ideal brittle materials. Therefore, the brittle fracture removal mechanism applies to the removed materials on the workpiece surface in brittle fracture mode as discussed by Arif [1],

2) All diamond particles in a drill bit cross section are taking part in cutting, and 3) All diamond particles are rigid, with octahedral shape of the same size with equal side length for the twelve sides.

In this research a mathematical model of ROP was developed using rotary ultrasonic drilling. The model contained process parameters, drill bit design parameters, an ultrasonic parameter and material parameters. This research investigated the effect of the drilling parameters appearing in the mathematical model for ROP performance. Drilling parameters based on the drilling process such as WOB and spindle head speed, parameters based on the drill bit design such as drill bit inner and outer diameters, abrasive particle size, and abrasive particles concentration, and finally an ultrasonic parameter such as the ultrasonic amplitude are the parameters were investigated in this study. The aforementioned parameters varied within an acceptable range and the mathematical model was used to show the predicted results.

A set of experiments was conducted on three different types of rocks that varied in strength: travertine, marble and basalt. In the experiments, the same drilling parameters in the mathematical model were varied showing the effect of each one of them on the drilling performance expressed as WOB. Finally, predicted results were compared with the experimental results in the efforts of validating the mathematical model expressed previously and presented again below:

$$
\begin{aligned}
& R O P=G_{1}\left(\frac{S_{a}^{1 / 4}}{C_{a}^{1 / 12}(t)^{9 / 8}\left(D_{a v g}\right)^{1 / 8}\left(\tan \frac{\alpha_{o}}{2}\right)^{3 / 4}}\right) \\
& \left(\frac{S(W O B)^{9 / 8}}{\left[\frac{\pi}{2}-\arcsin \left(1-\frac{\delta}{A}\right)\right]^{1 / 8}}\right)\left(\frac{E^{7 / 8}}{H_{v}^{3 / 2} K_{I C}^{1 / 2}\left(1-v^{2}\right)^{1 / 4}}\right)
\end{aligned}
$$

\section{Predicted versus experimental results}

The rotary ultrasonic drill used in these experiments is designed to use the feed rate as an input parameter providing the applied WOB on the workpiece as the measured output parameter. Therefore, and according to the above ROP expression, the mathematical model is validated by holding ROP constant and determining the applied WOB while holding the other parameters constant at nominal values. The determined WOB from the model is compared to the cutting force obtained in the experiments. This process is repeated as one variable at a time changes determining the effect it has on the cutting force. Using the same drill bit, the drilling was conducted in cutting through three different types of rocks with varied strength. The results show general agreement with the mathematical model developed except for the abrasive particle size as it was explained previously.

The predicted results agreed with experimental results showing that as the speed increased, the applied cutting force decreased. The decrease in cutting force as the speed increases while cutting through three different types of rocks was proportional to the material properties that varied in strength.

Although the model shows the same trend, it shows different values at above and below the nominal speed value of $2500 \mathrm{rpm}$. The reason for this difference is usually related to the method by which the volume proportionality $\mathrm{K}$ was determined. It is evident that the value of predicted speed matches the experimental results very accurately because $\mathrm{K}$ was determined at the nominal values of all parameters, including speed. The rest of the values, however, show a pattern of being larger of speed less the nominal and smaller for speeds that are larger than the nominal. As K remains constant for those values the WOB value drift away from the model.

The cutting force is an output parameter in the RUM used in this research. Therefore, the feed rate is used as an input parameter where it var- 
ied showing its effect on the output parameter of the cutting force. The experimental results agreed with the predicted results showing that as the feed rate/ROP increased the cutting force increased as well linearly. The increase in cutting force as the feed rate increases while cutting through three different types of rocks varied and it is proportional to the rock strength.

Again the value of the model matches very closely the experimental results at the nominal value. The model result was lower than the experimental values at ROP lower than the nominal value and larger at ROP larger than the nominal value. Again, the reason is the use of constant value of volume proportionality $\mathrm{K}$ may actually vary slightly than rather being an exact constant value as it was explained previously.

Four sizes of the abrasive particles were used in these experiments showing the effect of the change of size on the cutting force. The experimental results showed a different trend from the results of the mathematical model. The predicted results showed that as the abrasive particle size increases, the cutting force decreases while the experiments showed an increase in cutting force. The decrease in cutting force in the model and the increase in the experimental results as the abrasive particle increases while cutting through three different types of rocks.

Three different abrasive particle concentrations were used in this study. The experimental results agreed with the predicted results closely, showing that as the abrasive particles concentrations increases the cutting force also increases. The increase in cutting force as the abrasive particle concentration increases while cutting through three different types of rocks varied.

The change in the drill bit cross section area is achieved by varying the drill bit inner and outer diameter size. Three different sizes were used in this research. The experimental results agreed with the predicted results showing that as the drill bit inner and outer diameters change, maintaining same thickness throughout the experiments, the cutting force increased linearly. The increase in cutting force as the drill bit inner and outer diameter increase while cutting through three different types of rocks varied.

The ultrasonic amplitude is one of the input variables of the RUM and it was easily adjusted as desired through changing the power applied to operate the drill. In this study, the ultrasonic amplitude changed showing its effect on the cutting force. The experimental results generally agreed with the predicted results showing that the increase of the ultrasonic amplitude decreases the cutting force. The decrease in cutting force as the ultrasonic amplitude increases while cutting through three different types of rocks varied.

\section{Direction of future research}

Although the trends of the predicted results are consistent with the experimental results with the exception of the abrasive particle size, not all parameters showed significant effects that are worth optimization. For example, the change in cutting force as a result to the change of the abrasive particle concentration, drill bit outer and inner diameters, and ultrasonic amplitude were relatively small and had very little effect on the drill performance. Therefore, the parameters that showed significant effect on the WOB performance such as the change of the spindle speed and the feed rate (ROP) are considered for future investigation of drilling input parameter optimization.

The main goal motivating this research is to find a new drilling technique in brittle materials that is capable of achieving greater depth drilling on Mars than ever before. While previous missions drilled in a few centimeters, the latest mission revealed that it is critical to drill to the much greater depth of six meters. The current drilling technology, at the present time, is not capable of reaching such depth and new drilling mechanism ought to be investigated. This study provides a first step in this investigation by examining a new drilling technique in search for more efficient method than the conventional ones. The developed mathematical model coupled with the experimental data will be utilized to compare the drilling performance, primarily in ambient condition, to the currently drilling technique, rotary percussive drilling. The rotary percussive drilling performance is well documented and performance comparison will be conducted in the effort to determine the most efficient drilling technique for future investigation under Mars condition for future missions and whether or not the RUM technique is the drilling method of the future space exploration.

As previously mentioned, drilling under simulated Martian conditions is significantly different from drilling under terrestrial conditions for many reasons. Therefore, it is essential 
to consider future research investigating drill performance using RUM under simulated Martian conditions. Rotary percussive drilling performance under simulated Martian condition is also well documented and it will be used for performance comparison with the model and data developed in this research.

\section{Acknowledgment}

This material is based upon work supported by the National Science Foundation Graduate Research Fellowship under Grant No. (DGE0946797) and NASA Harriett G. Jenkins Predoctoral Fellowship Project Grant No. (NNX13AR83H)

\section{REFERENCES}

1. Arif M., Rahman M., San W. and Doshi N. 2011. An experimental approach to study the capability of end-milling for microcutting of glass. Int $\mathrm{J} \mathrm{Adv}$ Manuf Technol 53(9), 1063-1073.

2. Badescu M., Sherrit S., Olorunsola A., Aldrich J., Bao X., Bar-Cohen Y., Chang Z., Doran P.T., Fritsen C.H., Kenig F., McKay C.P., Murray A., Du S., Peterson T. and Song T. 2006. Ultrasonic/sonic gopher for subsurface ice and brine sampling: analysis and fabrication challenges, and testing results. Proceedings of the SPIE Smart Structures and Materials Symposium, San Diego, CA, 27 February-2 March 2006, Paper 6171-07.

3. Badescu M., Sherrit S., Bar-Cohen Y., Bao X. and Kassab S. 2007. Ultrasonic/sonic rotary-hammer drill (USRoHD). NTR Docket No. 44765, 19 December 2006. Patent application submitted $17 \mathrm{Au}-$ gust 2007.

4. Bar-Cohen Y. and Zacny K. (2008). Drilling in Extreme environments, WILEY-VCH Verlar $\mathrm{GmbH}$ \& Co. KGaA.

5. Cong W.L., Pei Z.J., Mohanty N., Van Vleet E. and Treadwell C. 2011. Vibration amplitude in rotary ultrasonic machining: A novel measurement method and effects of process variables. Journal of Manufacturing Science and Engineering, 133(June 2011), 034501. doi:10.1115/1.4004133.

6. Cong W., Pei Z., Deines T., Liu D. and Treadwell C. 2013. Rotary ultrasonic machining of CFRP/Ti stacks using variable feedrate. Composites Part B: Engineering, 52, 303-310. doi:10.1016/j.compositesb.2013.04.022.

7. Cong W., Pei Z., Sun X. and Zhang C. 2014. Rotary ultrasonic machining of CFRP: A mechanistic predictive model for cutting force. Ultrasonics, 54(2), 663-675. doi:10.1016/j.ultras.2013.09.005.

8. Griffith A.A. 1920. Phil. Trans. Roy. Soc. Lond. A221, 163.

9. Lawn B., Evans A.G. and Marshall D.B. 1980. Elastic/plastic indentation damage in ceramics: the median/radial crack system, Journal of the American Ceramic Society 63 (9-10), 574-581.

10. Lawn B. and Wilshaw R. 1975. Indentation fracture: principles and applications, Journal of Materials Science 10(6), 1049-1081.

11. Liu D., Cong W., Pei Z. and Tang Y. 2012. A cutting force model for rotary ultrasonic machining of brittle materials. International Journal of Machine Tools and Manufacture, 52(1), 77-84. doi:10.1016/j.ijmachtools.2011.09.006.

12. Marshall D.B., Lawn B.R. and Evans A.G. 1982. Elastic/plastic indentation damage in ceramics: the lateral crack system, Journal of the American Ceramic Society 65 (11), 561-566.

13. Ostojic P. and Mcpherson R. 1987. A review of indentation of fracture: its development, principles and limitations, International Journal of Fracture 33, 297-312.

14. Zhang C., Zhang J. and Feng P. 2013. Mathematical model for cutting force in rotary ultrasonic face milling of brittle materials. The International Journal of Advanced Manufacturing Technology, 69(14), 161-170. doi:10.1007/s00170-013-5004-z.

15. Zhao X.L., Fowell R.J., Roegiers J.-C. and Xu C. 1994. Rock fracture-toughness determination by the Brazilian test, by H. Guo, N.I. Aziz, L.C. Schmidt. Engineering Geology, 38, 181-184. doi:10.1016/0013-7952(94)90033-7. 